\title{
Research on Homogenization and Surface Integrity of Ti-6Al-4V Alloy by Longitudinal-Torsional Coupled Ultrasonic Vibration Ball-End Milling
}

\author{
Wanfei Ren ${ }^{1,2}$, Jinkai $\mathrm{Xu}^{1 *}$, Jieqiong $\mathrm{Lin}^{2}$, Zhanjiang $\mathrm{Yu}^{1}$, Peng $\mathrm{Yu}^{1}$, \\ Zhongxu Lian ${ }^{1}$ and Huadong $\mathrm{Yu}^{{ }^{*}}$
}

1 National and Local Joint Engineering Laboratory for Precision Manufacturing and Detection Technology, Changchun university of science and technology, Changchun 130012, Jilin PR China.renwanfei@ccut.edu.cn (W.R.); $261230500 @$ qq.com (Z.Y.); $1264740172 @$ qq.com (P.Y.); $771392850 @ q q . c o m(Z . L$.

2 School of Mechatronic Engineering, Changchun university of technology, Changchun 130012, Jilin PR China. renwanfei@ccut.edu.cn (W.R.); linjieqiong@ccut.edu.cn(J.L.)

* Corresponding author: xujinkai2000@163.com; yuhuadong@ cust.edu.cn.

\begin{abstract}
This paper aims to study the surface homogenization and integrity of Ti-6Al$4 \mathrm{~V}$ alloy by longitudinal-torsional coupled ultrasonic vibration assisted ball-end milling. A method of continuous processing between the flat surface and freeform surface connection is proposed by using ultrasonic vibration assisted ball-end precision milling, during this process, it is not necessary to exchange the cutting tool. The way has been explored for changing the homogenization of surface on Ti-6Al-4V by ultrasonic vibration-assisted milling (UVAM). Cutting experiments employing three parameters, cutting speed, feed rate and depth of cut and two types of machining forms using ballend milling with UVAM and conventional milling (CM) respectively. The high frequency cutting force, finished surface roughness, topography and residual stresses on the surface and tool wear have been measured by advanced instruments. Particularly, adopting the high frequency cutting force measurement system, it is concluded cutting force in ball-end milling decreased significantly using UVAM as against CM. Moreover, the surface roughness by UVAM with ball-end milling is much better than the CM at a high cutting speed. However, an opposite trend is observed at a low cutting speed. Especially, there is a steep decrease from $\mathrm{Ra} 0.828 \mu \mathrm{m}$ average value at $4000 \mathrm{rpm}$ to $\mathrm{Ra}$ $0.129 \mu \mathrm{m}$ average value at $5000 \mathrm{rpm}$. At the same time, the homogenization of surface roughness and residual stresses decrease significantly in UVAM as compared to which in $\mathrm{CM}$ when taking the transversal-longitudinal ratio into consideration. Cutting experiments and measuring results are demonstrated the validity and feasibility of UVAM with ball-end milling, and this method enjoys significant advantages compared to CM process.
\end{abstract}

Keywords: ultrasonic vibration-assisted milling(UVAM); homogenization; ball-end milling; surface integrity; high frequency cutting force 


\section{Introduction}

Recently, Ti-6Al-4V ( $\alpha-\beta$ titanium alloy), as one of and toughness difficult to process materials, high strength possesses superior mechanical and chemical properties (high hardness, high rigidity, excellent wear resistance, and good corrosion resistance) and has been widely applied especially in the fields of aeronautics and astronautics, defense industry, medical apparatus and instruments, automobile and energy and other fields. For the metal cutting process of Ti-6Al-4V, it has attracted extensive attention from the academic and engineering researchers, and has conducted in-depth research on the turning, drilling, planning, tapping and milling [1][2] of this material. However,Ti-6Al$4 \mathrm{~V}[3,4]$ generates a large amount of cutting heat in the conventional cutting process. In this case, the tool wear is severely in the cutting process.

According to this situation, it has become an effective method to apply ultrasonic vibration assistance on convention milling $(\mathrm{CM})$. Although there are many researches on ultrasonic vibration assistance turning [5], drilling [6,7] and grinding [8,9], few studies on ultrasonic vibration assisted milling (UVAM). UVAM has the advantages of high frequency response, reducing the cutting force, reducing the roughness of the machining surface, reducing the temperature in the cutting region, improving the residual stress state of surface, improving the processing efficiency, and extending the service life of the tool. Ball-end milling is necessary for fine milling the last step of complex surface including flat surface and freeform surface. In ordinary 3-axis milling machine, ball-end milling can only process incline and freeform surface, but not flat surface. The reason is that there is no cutting speed in the center of the ball-end milling cutter, which have adverse effects on the surface quality. The surface roughness can be improved significantly in the course of planar precision milling by using UVAM and choosing cutting parameters without tilting ball-end milling [10-12] cutter. In same scale, ultrasonic vibration assistance can extend the 3-axis machine fine milling function.

Tangjitsitcharoen [13] et al. studied a feasible method to predict the surface roughness during ball-end milling process by using dynamic cutting force rate. Fontaine et al. in their study deals with the effect of tool-surface inclination on cutting forces in ball-end milling, and established model is applied to ball-end milling with straight tool paths but with various tool-surface inclinations[14]. Buj-Corral [15] et al. in their recent research, a new numerical model is developed to predict surface morphology and surface roughness of ball head milling. However, the ball-end milling in CM application in above literatures, ultrasonic vibration assistance ball-end milling is rarely seen in previous studies.

In finished surface roughness research of machining, Feng et al. indicated rotary ultrasonic technology cannot significantly decrease the surface roughness where domestic scholars tended to think that rotary ultrasonic machining increased the surface roughness value, while the foreign scholars thought that rotary ultrasonic reduced the surface roughness value $[16,17]$. Tao et al. proposed a kinematic model and a pressing model for the formation mechanism of surface texture for feed-direction 
ultrasonic vibration assisted milling. But this research had less pay attention on the overlapping machining area [18]. Applying ultrasonic vibration in the feed direction [19-20] and main shaft axial direction [21] could change the surface quality via matching different cutting parameters. This paper reports on ball-end milling surface roughness value increasing or decreasing by UVAM and CM process in the overlapping area where should be taken into account carefully.

Suárez et al. illustrated the important effects of ultrasonic vibration assisted milling Ni-Alloy 718, such as the surface integrity of materials, tool wear, cutting force and fatigue resistance. In the cutting force analysis, the cutting force is hundreds Newtons and force mean values are very similar between conventional milling and ultrasonic vibration-assisted milling [22]. But in this study, the cutting force value by UVAM is in a few decades Newtons level and decrease compared to CM process. Zarchi et al. studied the cutting force, and the experimental results showed that the average cutting force of UVAM is less than CM [23]. The cutting force in traditional machining process is obtained by means of force measuring instrument. However, the cutting force generated in ultrasonic machining process is high-frequency cutting. It is hard to accurately measure high frequency cutting force by ordinary low frequency measurement.

Hampa et al. validated the effect of ultrasonic vibrations on the milling process of the stainless steels, a series of experiments were designed and then implemented on a difficult-to-machine material [24]. Abdullah designed and established a special experimental equipment which can apply one-dimensional vibration to the workpiece in order to study the ultrasonic assisted milling process [25]. At the same time, the surface residual stress [26] and other surface integrity hidden effects [27,28] of ultrasonic vibration assisted milling are also conducted in this paper. But little research successfully took surface homogenization into consideration both in roughness and residual stresses analysis.

As discussion above, there are some advantages and metrics in their research both in vibration cutting process. But little study on the homogenization on surface of ballend milling by UVAM. It is first time that proposed UVAM can transform the material surface layer homogenization. The ball-end milling surface roughness value increasing or decreasing by UVAM and CM process in the overlapping area should be taken into account carefully. It is impossible to accurately measure high frequency cutting force by ordinary low frequency measurement. Taking into account the ball-end with and without ultrasonic-assisted, the work compare each other in order to describe cutting finished surface integrity in detail.

\section{Experimental procedure}

\subsection{Experimental setup}

Figure 1 illustrates a schematic of the experimental system including main three parts: numerical control milling machining system, ultrasonic vibration system and 
cutting force data acquisition system.

The first part: milling machining system (Haas, VF-1, United States) which is used to conduct all the experiments both UVAM and CM. The experimental method of this experiment is practical in the study of processing mechanism, the numerical control (NC) milling machine system for a three-axis milling configuration, $\mathrm{X}, \mathrm{Y}$ and $\mathrm{Z}$-axis, and the rotation of the spindle axis of $\mathrm{Z}$-axis, and $\mathrm{X}, \mathrm{Y}$ and $\mathrm{Z}$ stage slide can move cooperative controlled by NC program. Cutting experiments are conducted in dry condition without any cutting coolant.

The second part: ultrasonic vibration system composed of a transducer and a booster, was employed to cause the workpiece material to vibrate by converting high-frequency oscillation electric power that is supplied by excitation induction into mechanical vibration. We selected ultrasonic tool shank at about $25 \mathrm{KHz}$ in which ball-end milling tools with diameter of $10 \mathrm{~mm}$ with two cutting flutes. Ultrasonic vibration system combines longitudinal initiative vibration along the axis of cutting tool with torsional vibration around milling cutter due to the addition helical flutes on the envelope surface.

The third part: cutting force data acquisition system is composed with Kistler dynamometer and VibRunner acquisition system which can deduce much data in per unit time.

And the cutting parameter were set in detail as show in the Table 1.

Table 1. Major experimental conditions

\begin{tabular}{lll}
\hline Prameter & Unit & Value \\
\hline Vibration frequency $(f)$ & $\mathrm{kHz}$ & About 25 \\
Vibration amplitude $(A)$ & $\mu \mathrm{m}$ & 5.6 \\
Spindle speed $(n)$ & $\mathrm{rpm}$ & $3000,4000,5000,6000$ \\
Cutting speed $\left(V_{c}\right)$ & $\mathrm{m} / \mathrm{min}$ & $94.2,125.6,157,188.4$ \\
Feed per tooth $\left(f_{z}\right)$ & $\mathrm{mm} / \mathrm{rev} \cdot$ th & $0.017,0.025,0.03,0.033$ \\
Feed rate $\left(V_{f}=f_{z}^{*} Z^{*} n\right)$ & $\mathrm{mm} / \mathrm{min}$ & $100,200,300,400$ \\
Depth of cut $\left(a_{p}\right)$ & $\mu \mathrm{m}$ & $20,40,60,80$ \\
Diameter of tool $(d)$ & $\mathrm{mm}$ & 10 \\
Path interval $\left(\Delta_{p}\right)$ & $\mu \mathrm{m}$ & 100 \\
Coolant & $/$ & None \\
\hline
\end{tabular}




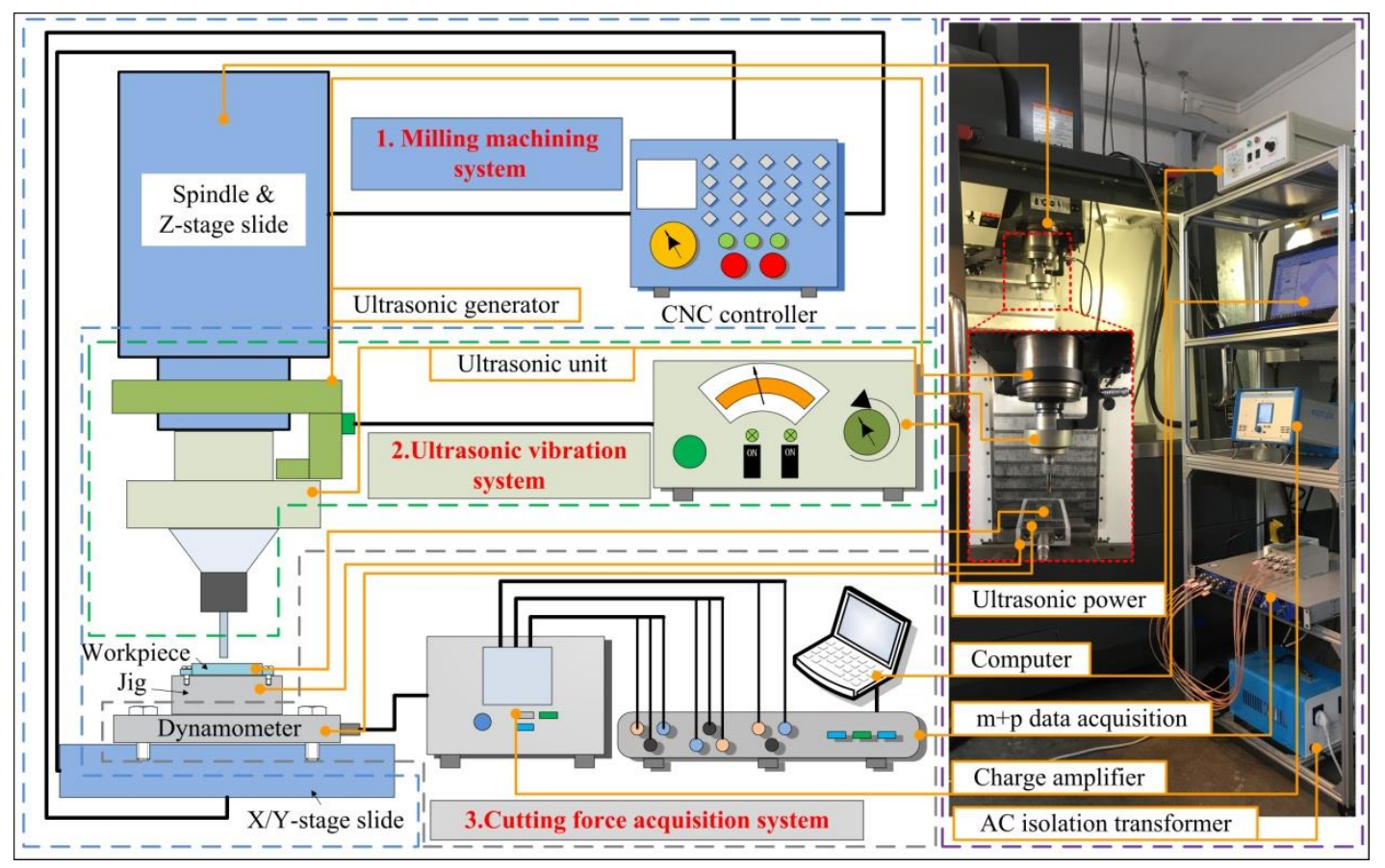

Figure 1. The scheme of UVAM and CM experimental system

The cutting force measurement system based on Kistler dynamometer and VibRunner data acquisition system which measured online. In order to accommodate the high working frequency of ultrasonic vibration device that approximately $25 \mathrm{kHz}$, VibRunner data acquisition system is selected to capture the high frequency signals.

This section explain the outline of the UVAM and CM process in which the third part accomplish the uniqueness on-line measure cutting force. And all the testing coupons in following experiments are manufactured based on this experimental platform.

\subsection{Materials and methods}

The workpiece is made up of Ti-6Al-4V alloy which dimension is $80 \times 34 \times 10 \mathrm{~mm}^{3}$ used both in ball-end milling experiments. Machined area was $60 \times 34 \mathrm{~mm}^{2}$ which allowed performing 8 different slots experiments with the ball-end mills with two flutes made up of same material with the same tool coating. To remove any residuals left on the workpiece, the tool is cleaned by a ultrasonic cleaners immersing in alcohol and then dried in the air before measurement. The material properties of Ti-6Al-4V displays in Table 2 in detail. In order to machine the surface point by point under ultrasonic process, the value of $\Delta p$ was set up as $100 \mu \mathrm{m}$. Because the high cutting temperature $\mathrm{Ti}$ is easy chemically with the oxygen in the air producing Ti oxide covered on the surface of workpiece. 
Table 2. Material properties of Ti-6Al-4V

\begin{tabular}{lll}
\hline Property & Unit & Value \\
\hline Density & $\mathrm{kg} / \mathrm{m} 3$ & 4510 \\
Hardness (Rockwell) & $\mathrm{HRC}$ & 36 \\
Elastic modulus & $\mathrm{GPa}$ & 113.8 \\
Tensile strength & $\mathrm{MPa}$ & 950 \\
Melting temperature & ${ }^{\circ} \mathrm{C}$ & 1660 \\
\hline
\end{tabular}

In order to analyze the cause of the surface homogenization, cutting zone and principle of ball-end milling by UVAM and CM process are both described in Figures 2 and 3 in detail. There are two directions to take into consideration.

Longitudinal direction: Along with the feed rate direction of milling cutter, the surface roughness, residual stresses and topography mainly depend on tool diameter and feed rate. The parameter $h_{L}$ presents the residual height of the surface in longitudinal direction;

Transversal direction: As show in Figure 3(a), the $\Delta_{p}$ and $R$ are the key factor influenced on transversal surface roughness, residual stresses and topography. The overlapping area of the tool path is a important parameter in which the diameter of milling cutter is $10 \mathrm{~mm}$ and the $\Delta_{p}$ is $100 \mu \mathrm{m}$. So almost all surface are machined by overlapping milling. The parameter $h_{T}$ presents the residual height of the surface in longitudinal direction.

In this paper, the homogenization of machined surface in both the directions introduction above contains surface roughness, residual stresses and topography measurements. It was found that the assisted feed direction ultrasonic vibration can achieve separate-type milling that is different from conventional operation by reasonable parameter matching [6]. The $z$ in CM process is the height from the point end $A$ of milling tool to the uncut surface in Figures 2 along the axis of tool. The maximum valid radius of cutting tool is defined as function (1):

$$
\left\{\begin{array}{l}
0 \leq z \leq R: R(z)=\sqrt{R^{2}-(R-\mathrm{z})^{2}} \\
z>R: R(z)=R
\end{array}\right.
$$

where the $R$ denotes radius of ball end; $R(z)$ denote the maximum valid radius of cutting tool. $z$ is the height from the tool point end to the uncut surface in Z-axis.

While in the UVAM process the maximum valid radius of cutting tool $R(z)$ is defined as formula(2), maximum valid radius of cutting tool $R(z)$ is varying in the range of the ultrasonic amplitude of cutting tool:

$$
\left\{\begin{array}{l}
0 \leq z \leq R: R(z)=\sqrt{R^{2}-[R-Z(\mathrm{t})]^{2}}=\sqrt{R^{2}-[R-(A \sin (2 \pi f t)+\mathrm{z})]^{2}}, \\
z>R: R(z)=R
\end{array}\right.
$$

where the $R$ denotes radius of ball end; $R(z)$ denotes the maximum valid radius of cutting tool; $Z(t)$ is the actual tool displacement in the formula(9) as follows define; $A$ 
denotes the ultrasonic amplitude; $f$ is the ultrasonic frequency.

The residual height of the cutting tool along longitudinal and transversal direction have been defined as follows.

$$
H_{L}=R-\frac{1}{2} \sqrt{4 R^{2}-f_{z}^{2}}
$$

where $H_{L}$ denotes the longitudinal residual height; $R$ is the radii of the ball-end; $f_{z}$ is the feed per tooth.

$$
H_{T}=R-\frac{1}{2} \sqrt{4 R^{2}-\Delta_{P}^{2}}
$$

where $H_{T}$ denotes the transversal residual height; $R$ is the radii of the ball-end; $\Delta_{p}$ is the path interval. The reason of the exists residual height apparently from the above analysis in formula(3) and formula(4). So the value of $f_{z}$ and $\Delta_{p}$ are the important parameters in the calculation of surface residual height.

The linear velocity of milling cutter ball end $\mathrm{V}$ in $\mathrm{CM}$ process can be defined as follows:

$$
V=\omega \cdot R(z)
$$

where the $\omega$ is the spindle frequency in $\mathrm{rad} / \mathrm{s}$ of milling cutter ball end.

while The linear velocity of milling cutter ball end V in UVAM process can be defined as follows:

$$
V=\omega \cdot \sqrt{R^{2}-[R-(A \sin (2 \pi f t)+z)]^{2}}
$$

Moreover, $\omega$ in UVAM is also different compared to which in CM. The cause of spindle speed more larger than the spindle speed in Table .2 is the ultrasonic torsional vibration. This phenomenon will discuss in the future research.

The trajectory of point $\mathrm{P}$ is defined as follow 3 formulas.

$$
\begin{gathered}
X(t)=R(z) \cdot \sin (\omega t) \\
Y(t)=R(z) \cdot \cos (\omega t)+V_{f} \cdot t \\
Z(t)=A \sin (2 \pi f t)+z
\end{gathered}
$$

where $\omega$ is the angular velocity of milling cutter ball end; $V_{f}$ is the feed rate of cutting; $A$ is the amplitude of ultrasonic; $f$ is the frequency of ultrasonic and $z$ is the height along $\mathrm{Z}$-axis from the point $A$ to the cutting face.

Ultrasonic vibration cutting improves the stiffness of the process system, and obviously improves the dynamic stability in the process of cutting, and then reduces the bending error and run-out error of the cutting tool.

In the direction of ultrasonic applied, according to the ball-end mill displacement $Z(t), v(t)$ is calculated as follows:

$$
\begin{gathered}
v_{x}(t)=X^{\prime}(t)=\omega R(z) \cos (\omega t) \\
v_{\mathrm{y}}(t)=Y^{\prime}(t)=-\omega R(z) \sin (\omega t)+V_{f}
\end{gathered}
$$




$$
v_{\mathrm{z}}(t)=Z^{\prime}(t)=2 \pi f A \cos (2 \pi f t)
$$

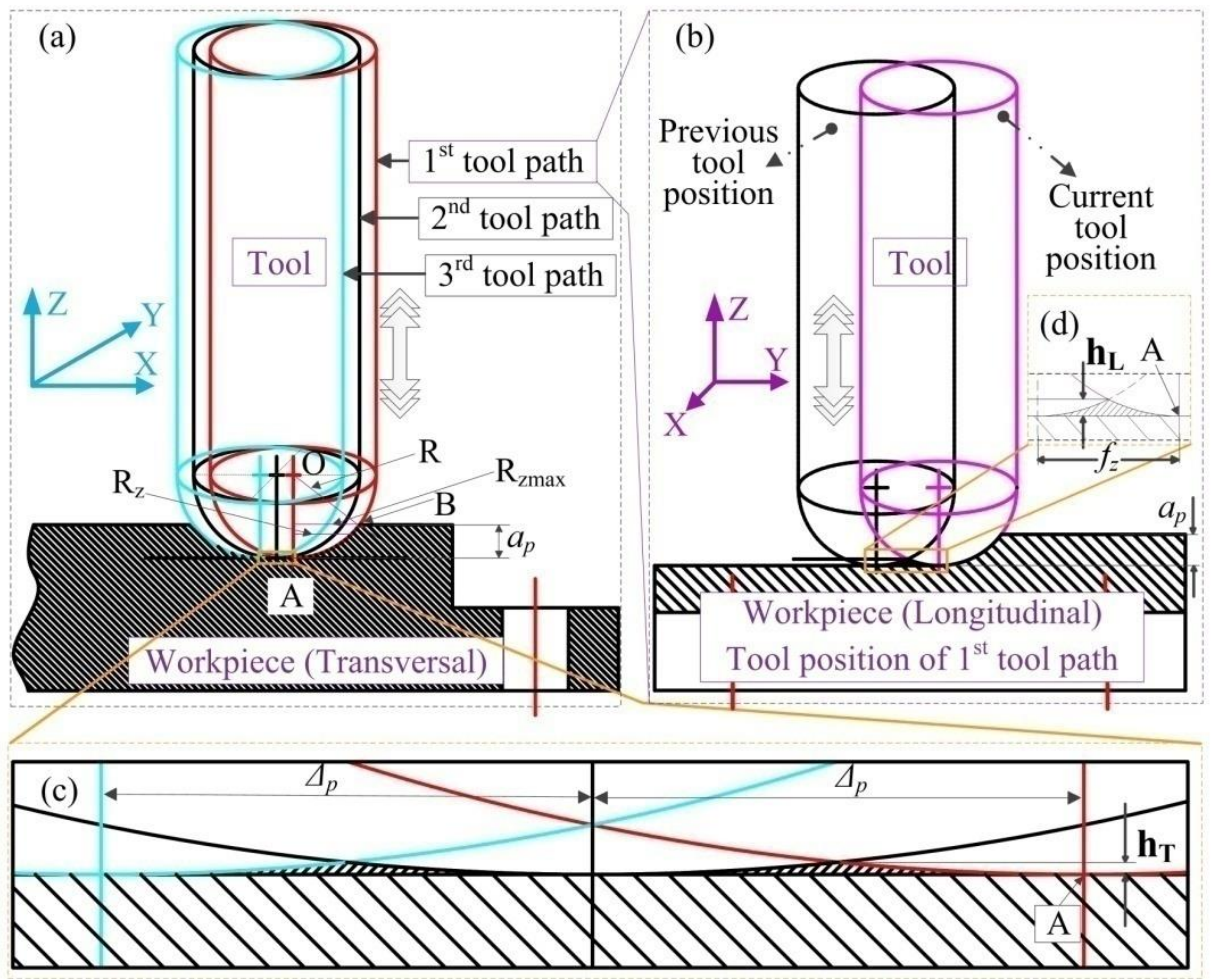

Figure 2. The cutting principle of ball-end milling: (a) the transversal residual height display;

(b) the longitudinal residual height display; (c) the longitudinal residual height display in detail;

(d) the transversal residual height display in detail

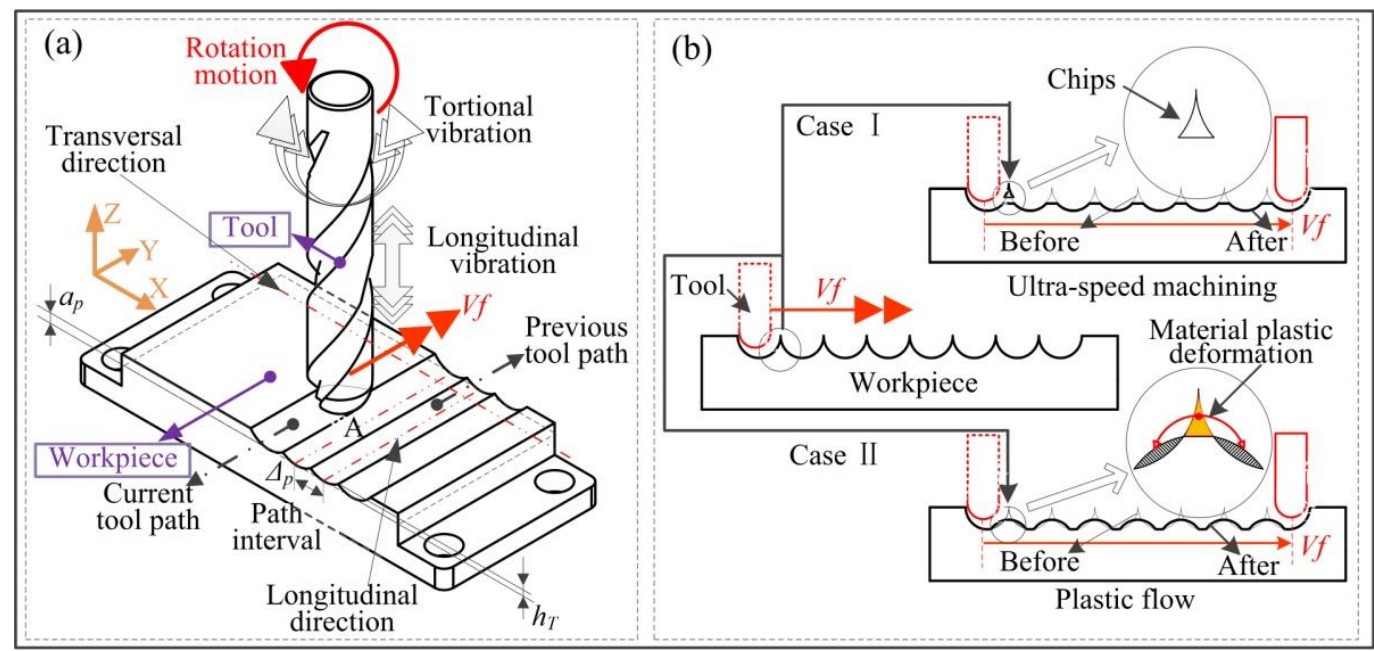

Figure 3. Cutting principle (a): Ball-end milling cutting principle of UVAM; (b):The two models of UVAM secondary processing: case I : ultra-speed machining; case II : material plastic deformation

As the same of the last step, according to the ball-end mill velocity $v(t)$ in ultrasonic applied direction, $a(t)$ is calculated as follows:

$$
a_{x}(t)=X^{\prime \prime}(t)=-\omega^{2} R(z) \sin (\omega t)
$$


The acceleration of other two axis can be defined as formula(14) and formula(15).

$$
\begin{gathered}
a_{y}(t)=Y^{\prime \prime}(t)=-\omega^{2} R(z) \cos (\omega t) \\
a_{Z}(t)=Z^{\prime \prime}(t)=-4 \pi^{2} f^{2} A \sin (2 \pi f t)
\end{gathered}
$$

Because the $v_{z}(t)$ is orthogonal to the feed rate direction, so the value of $v_{z}(t)$ can always reduce intermittent cutting compared to the ultrasonic applied in the feed direction [16]. Due to the ultrasonic vibration assistance process, a high frequency instantaneous acceleration will apply on the end point of ball-end miller. At such a high acceleration, large vibration stress will reduced inside the material. So the residual stresses and hardness of the material surface will change correspondingly.

There are two cases in the small differences in the cutting process at the last step in processing. In ball-end milling, two cases as followed are contributed to the finished surface including surface roughness and topography.

Case I: The peak value of the residual height (the value of $h_{T}$ and $h_{L}$ ) on the surface machined by conventional cutting method and ultrasonic vibration assisted machining method respectively. In this case, the ultrasonic ultraspeed milling process just like the grinding process illustrated in Figure 3(b), and reducing the smaller cutting chips which almost cannot be collected by routine methods, but the little chips will be found in the workpiece finished surface and the surface of cutting tool.

Although this is one of the theories we can explain the improving quality of surface machined by the UVAM, there is a cutting model we establish to evaluate the ultrasonic vibration function in the milling process.

Case II: We set the peak of residual height (the value of $\mathrm{h}_{\mathrm{T}}$ and $\mathrm{h}_{\mathrm{L}}$ ) on the surface as a solid that can be plastically deformed in a certain scale, so we have reasons to believe that the ultrasonic vibration enhancing the stiffness of the cutter. Because the velocity in center of the milling cutter is zero (rotation radii is zero), the center point of ball-end milling cutter do not participate in the cutting motion that was also illustrated in Figure 3(b). Moreover, the rigid cutter center will squeeze the surface just like a high frequency hammering action under the UVAM, the peak of residual height will squeeze into the valley between two peak on the surface in the micro level.

As we all known in Figure 3(b), the surface roughness Ra contains almost the cutting information, including cutting force, cutting state, invisible information and so on. In this section, we established a relation in qualitative analysis between surface roughness and cutting parameters as follows.

$$
R \mathrm{a}=k_{1} \cdot V_{c}^{\xi_{1}} \cdot f_{z}^{\xi_{2}} \cdot a_{p}^{\xi_{3}}+k_{2} \cdot f^{\xi_{4}} \cdot A^{\xi_{5}}+k_{3} \cdot \tau_{\text {plas }}^{\xi_{6}}
$$

where the two impact factors of $R a$ are the CM parameters and ultrasonic vibration parameters; $k_{l}$ is the ratio parameter of CM process; $V_{c}$ is the cutting speed; $\xi_{1}$ is the cutting speed coefficient; $f_{z}$ is the feed rate per tooth; $\xi_{2}$ is the feed rate per tooth coefficient; $a_{p}$ is the depth of cut; $\xi_{3}$ is the depth of cut coefficient; $k_{2}$ is the ratio parameter of UVAM process; $f$ is the frequency of the ultrasonic; $\xi_{4}$ is the frequency coefficient; $A$ is the amplitude of the ultrasonic; $\xi_{5}$ is the amplitude coefficient; $k_{3}$ is the ratio parameter of plastic flow process; $\tau_{\text {plas }}$ is the plastic deformation parameter; $\xi_{6}$ is 
the plastic deformation coefficient

The relation between $k_{1}, k_{2}$ and $k_{3}$ as follows:

$$
k_{1}+k_{2}+k_{3}=1
$$

In this formula, we just proposed the qualitative analysis model, and quantitative analysis of this model will carry out in future work.

\section{Experimental results and discussion}

\subsection{Finished surface roughness}

The surface roughness is closely related to the wear resistance, fatigue strength, contact stiffness of mechanical parts, and has an important influence on the service life of products, and is one of direct cutting process proofs [2]. There are 256 groups of experiment about surface roughness measurement including along with longitudinal and transversal direction with and without ultrasonic assisted processing. During the experiment, it is found that when ultrasonic vibration is used to machine the surface of the workpiece, the surface roughness changes significantly from spindle rotation speed $4000 \mathrm{rpm}$ to $5000 \mathrm{rpm}$. The surface milled by UVAM is all overlapping area according to the small value path interval $\Delta_{p}$.

Figure 4 compares surface roughness in ball-end milling of Ti-6Al-4V with UVAM and $\mathrm{CM}$ process along longitudinal and transversal direction. The surfaces roughness is measured on surface profilometer (Mahr, MarSurf LD 120, Germany). In order to detect the cutting parameter influenced on the surface roughness, a series of measurement experiments are conducted on the slots surface. As we can see clearly in Figure 4, the roughness value of UVAM ball-end milling in 5000-6000 rpm is obvious below than $\mathrm{CM}$ in the same parameter, but this phenomenon does not reappear in the lower spindle speed. The surface roughness depends heavily on the cutting speed value. It is found that when ultrasonic vibration is used to machine the surface of the workpiece, the surface roughness changes significantly from $4000 \mathrm{rpm}$ to $5000 \mathrm{rpm}$. The surface roughness averages Ra $0.828 \mu \mathrm{m}$ in a range of 3000-4000 rpm. However, it decreases to $\mathrm{Ra} 0.129 \mu \mathrm{m}$ in a range of $5000-6000 \mathrm{rpm}$, and the black dot curve is the transverse bottom roughness of slots in the same trend with longitudinal direction. The red solid curve of the longitudinal surface roughness variable trend have no great difference both in low and high spindle speed in ball-end CM, at the same time, the transverse direction roughness in the red dot curve is little higher than that in the longitudinal direction. In the range of the experimental parameters, when the spindle speed exceeds $5000 \mathrm{rpm}$ according to the spindle speed single-tooth frequency of $83.3 \mathrm{~Hz}$. Matching the ultrasonic frequency (approximately $25 \mathrm{KHz}$ ), the torsional vibration greatly increases the rotation speed of spindle to some extent. The tool-workpiece relative speed is so high equivalent to ultra-speed milling. During the experiment, consequently, we can conclude the roughness value $\mathrm{Ra}$ is below $0.27 \mu \mathrm{m}$ in ball-end milling with the spindle speed exceed $5000 \mathrm{rpm}$. 


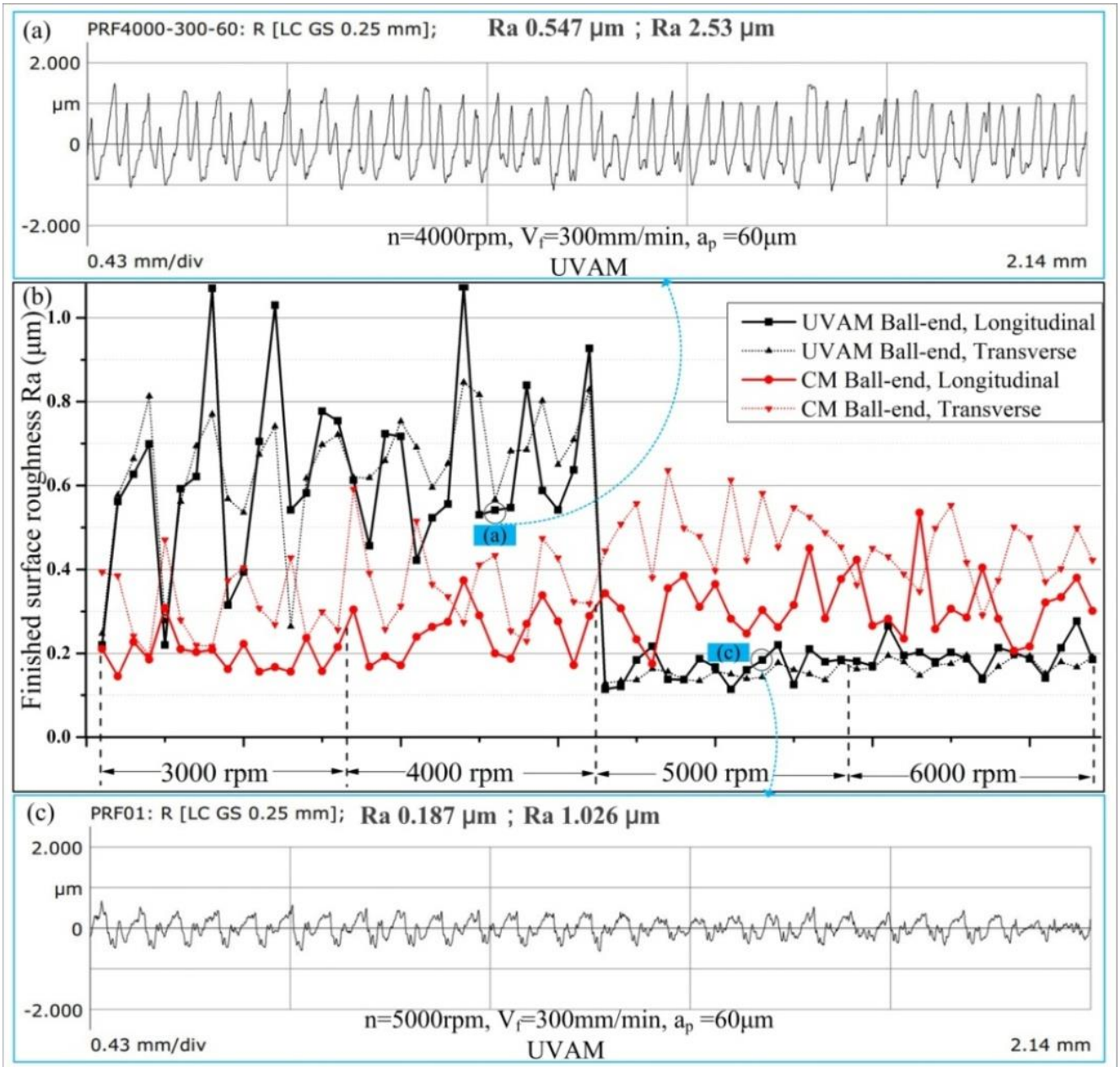

Figure 4. Finished surface roughness cutting by UVAM and CM: (a) is the real surface roughness in $\mathrm{n}=4000 \mathrm{rpm}, \mathrm{V}_{\mathrm{f}}=300 \mathrm{~mm} / \mathrm{min}, \mathrm{a}_{\mathrm{p}}=60 \mu \mathrm{m}$; (b) is the whole surface roughness value of 256 groups; (c) is the real surface roughness in $\mathrm{n}=5000 \mathrm{rpm}, \mathrm{V}_{\mathrm{f}}=300 \mathrm{~mm} / \mathrm{min}, \mathrm{a}_{\mathrm{p}}=60 \mu \mathrm{m}$

Figure 5 displays the homogenization about roughness of slots surface. The homogenization of surface roughness decrease significantly in UVAM as compared to which in CM when taking the transversal-longitudinal ratio into consideration. The transversal-longitudinal ratio is the absolute of value of transversal-longitudinal to the longitudinal value. The homogenization of roughness in UVAM is $17.95 \%$, which is significantly improved as compared with $61.18 \%$ in the traditional milling. We can clearly find the homogenization of ball-end milling with ultrasonic in black color is more lower than homogenization of CM in red color of the bar chart.

After 256 groups of surface roughness measurements were performed, in ball-end milling under ultrasonic assisted process along with the cutting speed (spindle speed) increasing, the slots surface roughness have a significant change. In the low spindle speed, the surface roughness of slots by UVAM is higher than by CM, but in high spindle speed, there is a different trend in roughness. So in ball-end milling, there are conspicuous advantages in high cutting speed. It should be noted that this study has conducted in only two orthogonal direction not considering the arbitrary directions. 


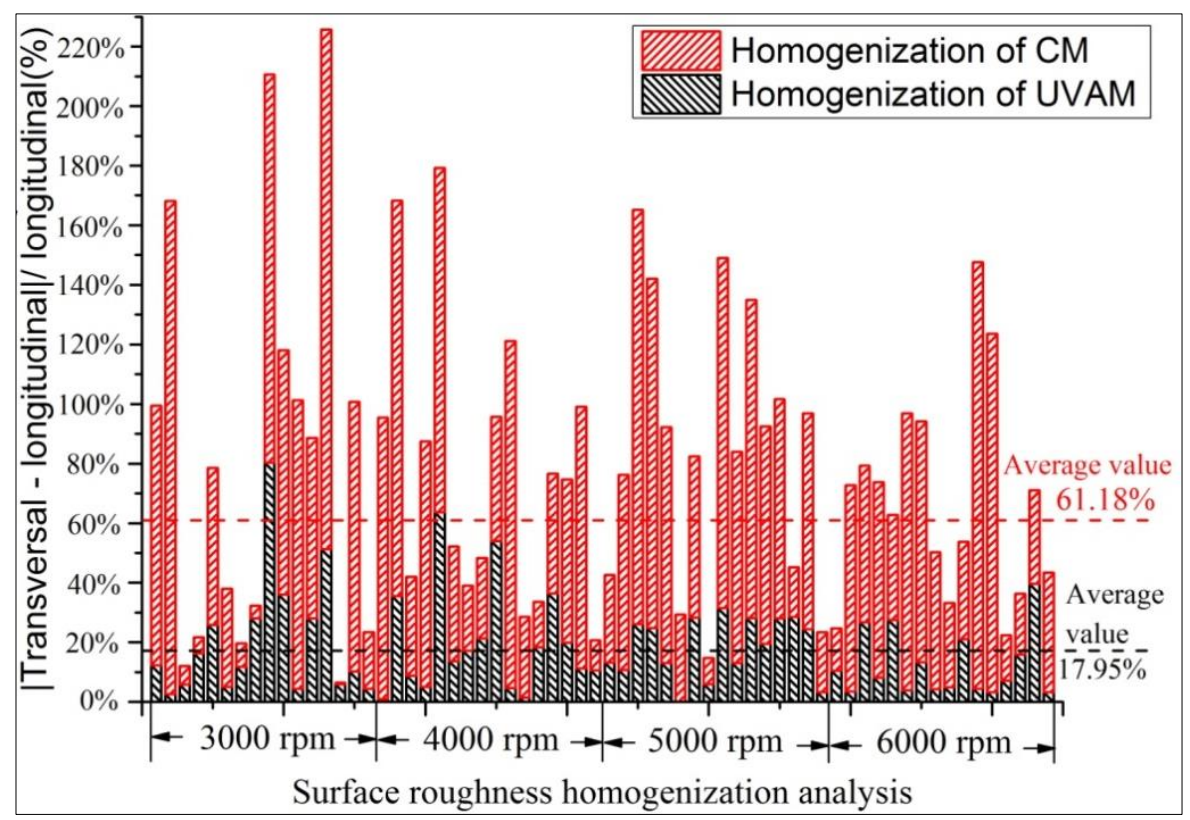

Figure 5. Homogenization of finished surface roughness

\subsection{Cutting force and chips analysis}

Online high frequency cutting force was measured during the cutting by a new established measurement system. A calibrated Dynamometer (Model 9256CQ01, Kistler Inc., Switzerland) is used to measure high frequency (about $25 \mathrm{kHz}$ ) cutting force during ultrasonic vibration milling process. The electronic signal from the dynamometer is amplified by a charge amplifier (Model 5070A, Kistler Inc., Switzerland) and then converts into a digital signal by A/D converter. With assisted by SO Analyzer $(\mathrm{m}+\mathrm{p}$ international, Germany), digital signal is collected by VibRunner $(\mathrm{m}+\mathrm{p}$ international, Germany) data acquisition card which maximum sampling frequency is $51.2 \mathrm{KHz}$ communicated with the computer. Because the system of Kistler data acquisition system cannot satisfy the high frequency force data acquisition, so we combined the Kistler 6-components dynamometer 9256CQ01 and VibRunner acquisition card together to obtain the online cutting force data.

In order to satisfy the high working frequency signal which obtained abundant data in short time analysis process requirements, VibRunner data acquisition system is utilized instead of Dynaware (Kistler Inc., Switzerland). UVAM process working in frequency of approximately $25 \mathrm{kHz}$, VibRunner data acquisition system is selected to deal with and store data processing.

Cutting force mainly consists of chip deformation force, friction force and ultrasonic impact force three parts in the ball-end milling with ultrasonic vibration assisted process. Under the same cutting parameters, the ultrasonic milling force is smaller than the traditional milling force, and the peak force mainly depends on the matching of three parameters: spindle speed, feed rate and cutting depth. Total time 20 s has been selected as the cutting time we acquire, so the total time contains 506000 times ultrasonic cutting circles. The cutting force data is obtained from the more steady cutting state in the whole cutting process. After acquired cutting force data both in UVAM and CM process, 
eight channels data has been calculated in a some formulas. The FX, FY and FZ is calculated according to the SO Analyzer software data storage information.

Not like to reduction of cutting force up to $70 \%$ in the ultrasonic continuous turning $[5,17]$ and grinding, the cutting force of milling process is original intermittent cutting process decreasing in a small scale with the ultrasonic vibration assistance. Figure 6 can clear illustrate the difference about cutting force both in the UVAM and CM process. In the UVAM process, the cutting force in $20 \mathrm{~s}$ is much lower than that by CM process both in the maximum force value and the average force value [18]. Ultrasonic vibration cutting force is uniform in a short period occupying whole cutting data time, at the same time, the cutting force in CM process is changing slowly and much higher than the ultrasonic one.

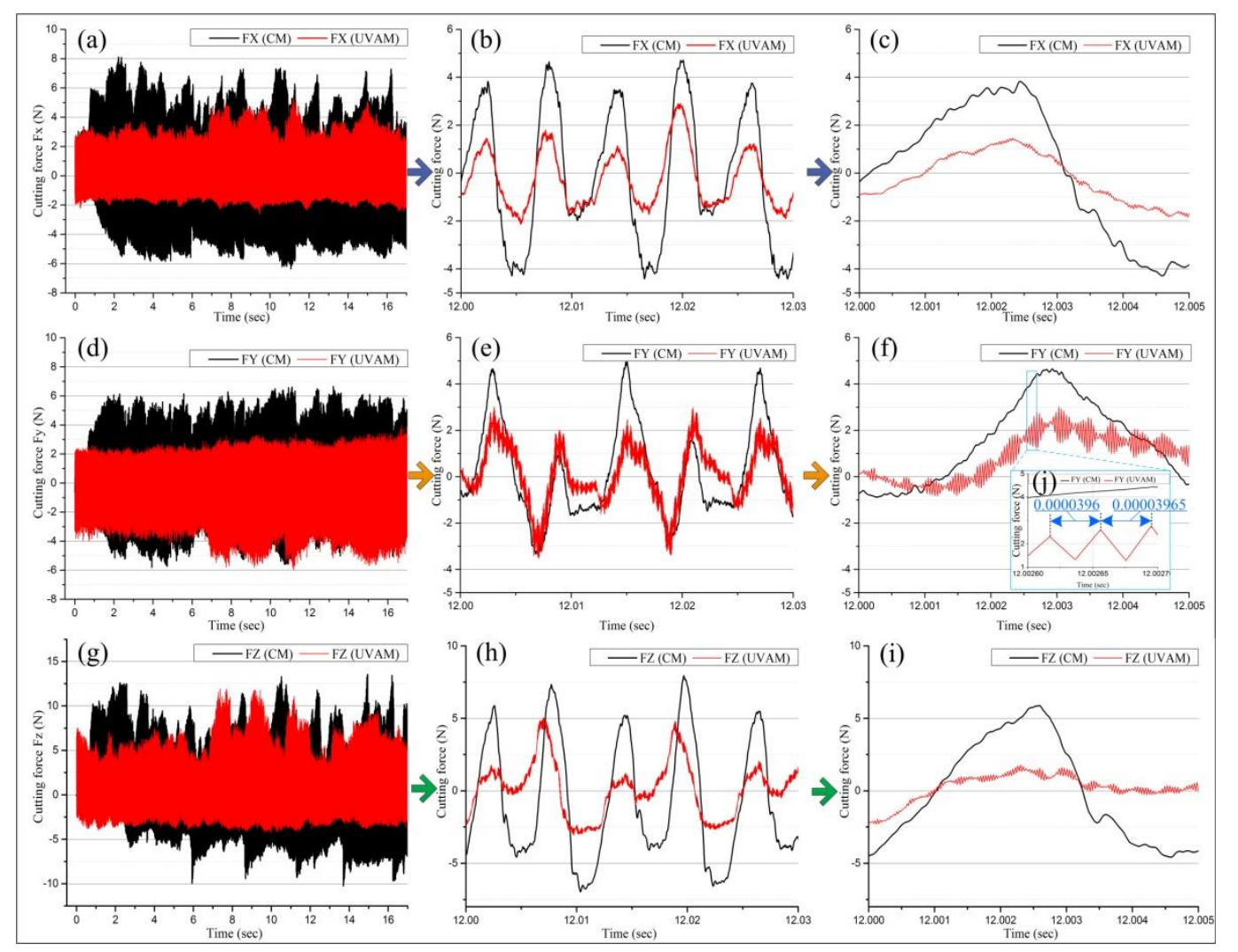

Figure 6. The cutting force of the UVAM and CM process, where $n=5000 \mathrm{rpm}, \mathrm{V}_{\mathrm{f}}=400 \mathrm{~mm} / \mathrm{min}, \mathrm{a}_{\mathrm{p}}=20$ $\mu \mathrm{m}$ : (a) is the cutting force along X-axis in $16 \mathrm{~s}$; (b) is cutting force along X-axis in $0.03 \mathrm{~s}$; (c) is cutting force along X-axis in $0.005 \mathrm{~s}$; (d) is the cutting force along Y-axis in $16 \mathrm{~s}$; (e) is cutting force along Yaxis in $0.03 \mathrm{~s}$; (f) is cutting force along Y-axis in $0.005 \mathrm{~s}$; (g) is the cutting force along Z-axis in $16 \mathrm{~s}$; (h) is cutting force along $\mathrm{Z}$-axis in $0.03 \mathrm{~s}$; (i) is cutting force along Z-axis in $0.005 \mathrm{~s}$; (j) is the cutting force along Y-axis in $0.0001 \mathrm{~s}$

As shown in the Figure 6, the fluctuation range of ultrasonic vibration cutting force in red curve is obviously smaller than that black curve of conventional cutting. Compared to the CM process, the cutting force of UVAM process decreased obviously in all three directions. The average value of FX in UVAM decreased about $48.14 \%$ than CM process in Figure 6(a). At the same time, the average value of FY also reduces about $21.04 \%$ in Figure 6(d). Besides the average value of FZ decreases about 35.76\% in Figure $6(\mathrm{~g})$. Selecting the time of $12 \mathrm{~s}$ after the beginning of acquisition cutting force, 
enlarge view is displayed in Figure 6(b), 6(e) and 6(h). In middle column of Figure 6, the value of cutting force is clearly compared with two cutting methods. For the next column following the middle one, secondary amplification view in the point of $12 \mathrm{~s}$, we can find that ultrasonic vibration curve different from conventional ones in detail, especially in the Figure 6(f) and 6(i) graphs where the signal of ultrasonic vibration components was noteworthy the discrepancies induced the homogenization and surface integrity of surface. The other parameters of cutting force cannot describe in detail, but ultrasonic vibration component also have a positively effect on the cutting force decreasing.

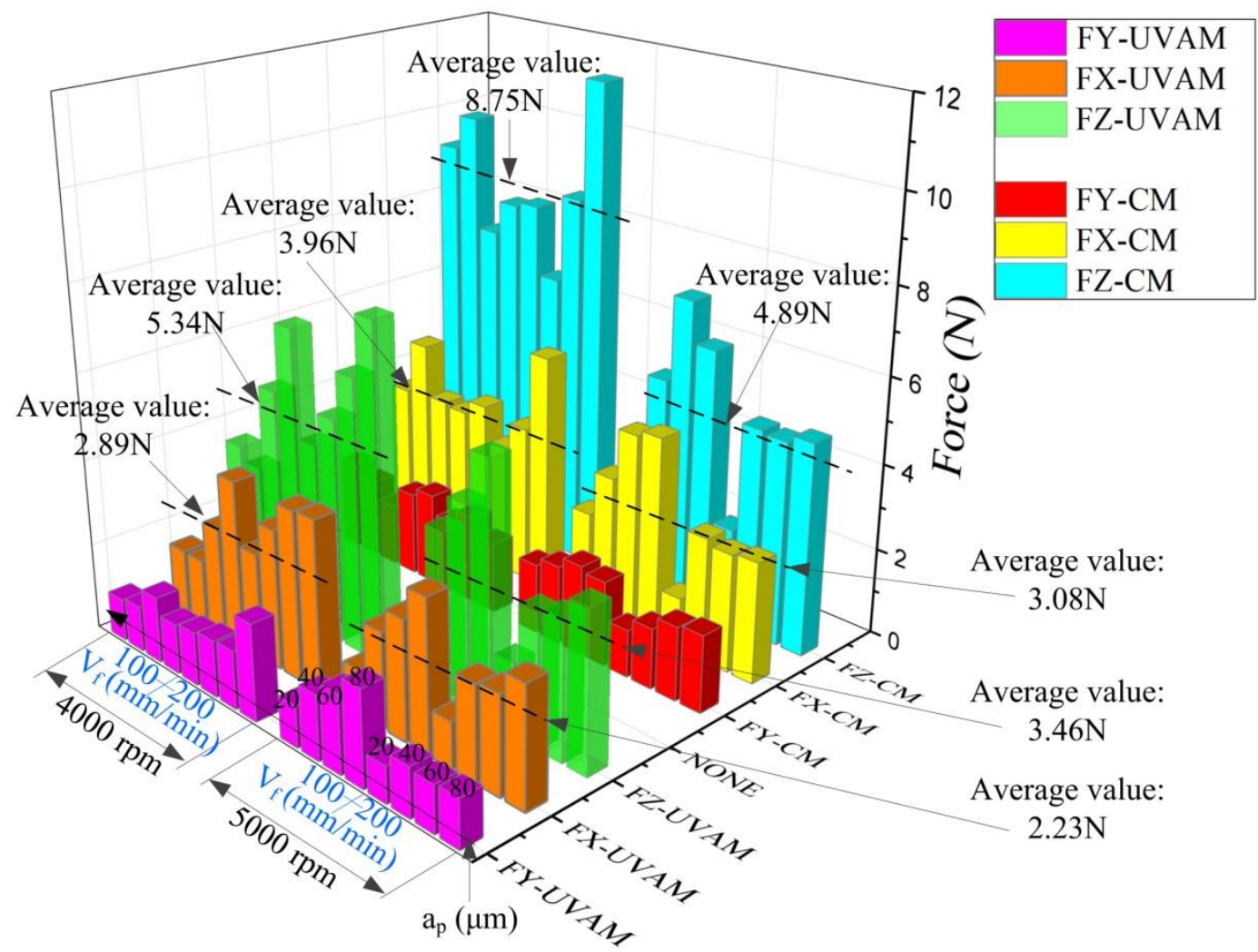

Figure 7. The average value of cutting force both in UVAM and CM process with the cutting parameter $n=4000 / 5000 \mathrm{rpm}, V_{f}=100 / 200 \mathrm{~mm} / \mathrm{min}$ with different cutting depth from $20 \mu \mathrm{m}$ to $80 \mu \mathrm{m}$ in 4 intervals.

In the Figure 7, there is a big difference of average value between the UVAM and CM process. The cutting average value of cutting force in $5000 \mathrm{rpm}$ with the UVAM process is $3.46 \mathrm{~N}$, which in CM process is $4.89 \mathrm{~N}$. At the same time, the average cutting force value in $5000 \mathrm{rpm}$ more less than value in $4000 \mathrm{rpm}$ with the same cutting parameters. As we concerned, the cutting force value in $Y$ axis is also more less than $X$ and $\mathrm{Z}$ axis cutting force value. Among 3 directions cutting force value, $\mathrm{Z}$ axis cutting force is the maximum value both in UVAM and CM process, because the $Z$ axis is the thrust force direction. Besides, in UVAM process, the cutting force is positive corresponding with the cutting depth both in the spindle speed in 4000 and $5000 \mathrm{rpm}$. However, the phenomenon in CM process is not very regular. In the homogenization of cutting force analysis, the average value of cutting force in $\mathrm{X}$ and $\mathrm{Y}$ axis was measured and calculated. In Table 3, the average value of cutting force in $n=5000 \mathrm{rpm}$ is lower than the spindle in $4000 \mathrm{rpm}$. The homogenization in UVAM the transversal- 
longitudinal ratio is $47.65 \%$, at the same time the transversal-longitudinal ratio is $49.15 \%$ little more than the UVAM process. The transversal-longitudinal ratio is the absolute of value of transversal-longitudinal to the longitudinal value. The homogenization is not significant in cutting force measurement.

Table 3. The homogenization of cutting force

\begin{tabular}{|c|c|c|c|c|}
\hline \multirow{2}{*}{$\begin{array}{c}\text { Average value of cutting } \\
\text { force }\end{array}$} & \multicolumn{4}{|c|}{$4000 \mathrm{rpm}-5000 \mathrm{rpm}$} \\
\cline { 2 - 5 } & FX (N) & FY (N) & FX-FY (N) & $\%$ \\
\hline UVAM & 2.56 & 1.34 & 1.22 & 47.65 \\
\hline CM & 3.52 & 1.79 & 1.73 & 49.15 \\
\hline
\end{tabular}
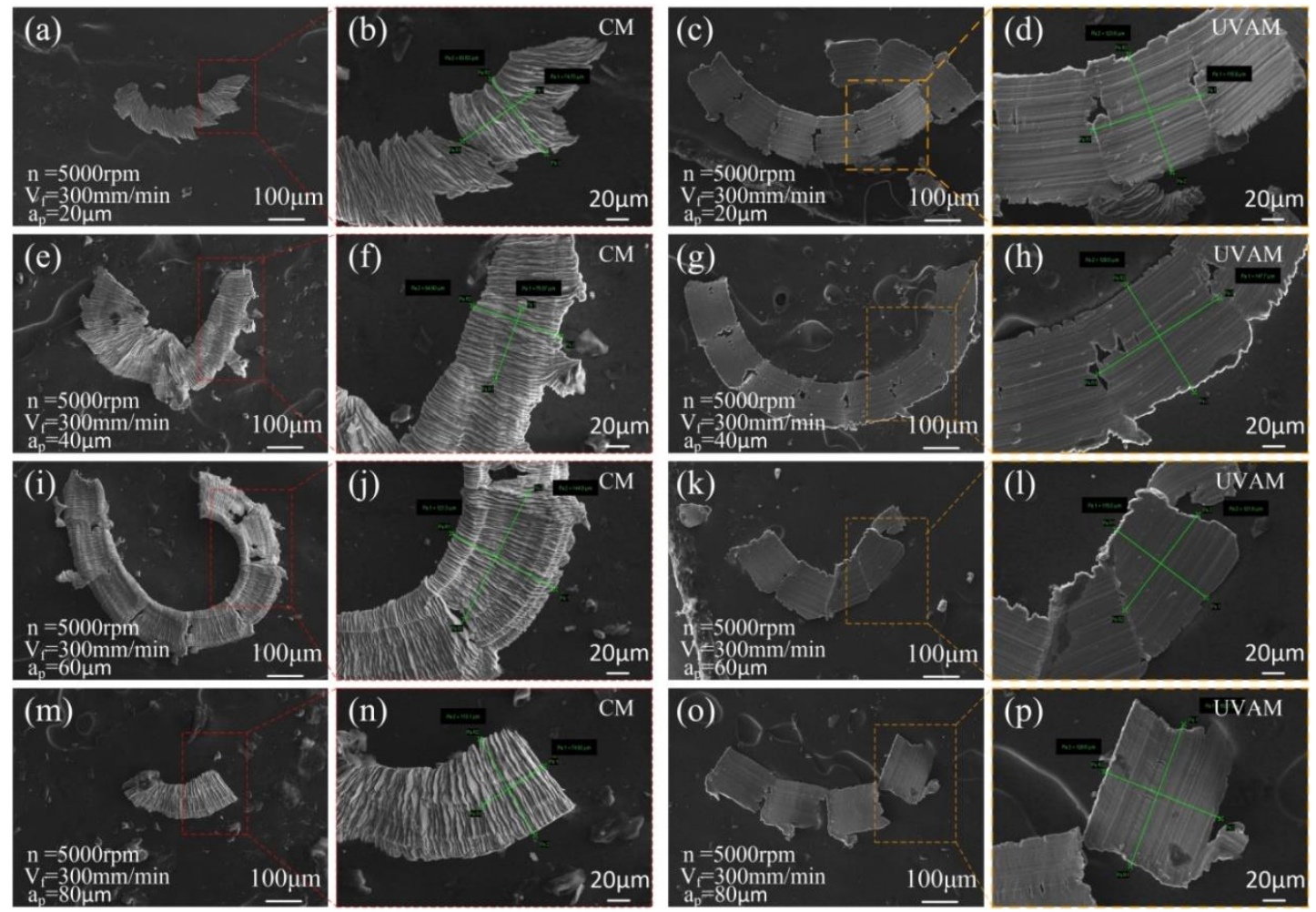

Figure 8. The chip images of scanning electron microscope both in UVAM and CM process with the cutting parameter $n=5000 \mathrm{rpm}$ and $V_{f}=300 \mathrm{~mm} / \mathrm{min}$ : (a), (e), (i) and (m) is the in CM process with varying cutting depth from $20 \mu \mathrm{m}$ to $80 \mu \mathrm{m}$, and (b), (f), (j) and (n) is the enlarger view of CM process; (c), (g), (k) and (o) is the in UVAM process with varying cutting depth from $20 \mu \mathrm{m}$ to $80 \mu \mathrm{m}$, and (d), (h), (l) and (p) is the enlarger view of UVAM process

As the most important proof of the cutting force, Figure 8 illustrates the cutting chips with the cutting parameter $n=5000 \mathrm{rpm}, V_{f}=300 \mathrm{~mm} / \mathrm{min}$ and varying cutting depth of $20 \mu \mathrm{m}$ to $80 \mu \mathrm{m}$ both in UVAM and CM process. The chips of back side view in CM process Figure 8(a), Figure 8(e), Figure $8(\mathrm{i})$ and Figure $8(\mathrm{~m})$ is more continuously than UVAM with big deformation, so that the chips is in a shape of $C$ type. It is hard to break into more smaller chips, and it is difficult to distinguish the edges between chips. On the cutting chips, fibrosis phenomenon has been found in curved inner circular surface 
where transformation bands with obvious organizational refinement. The adiabatic shearing slip and plastic fracture dimples were found in the deformation zone. Especially, in the view of Figure 8(e), the cutting chip indicates the big deformation not only the milling force in this section but also some squeeze phenomenon occurs at the same time in surface materials along with the larger cutting force. Consequently, this is another proof for the cutting deformation between workpiece and the end point of the ball-end mill.

In the Figure 8(j), the cutting period time in the red curve by UVAM is about 0.0396 $\mathrm{ms}$, the time corresponds to a frequency of $25.25 \mathrm{kHz}$ which is very closed to the ultrasonic frequency we used in this literature. According to this short period time, ultrasonic vibration has a important function in ball-end milling. This micrograph validates the ultrasonic assistance can decrease the roughness value from $\mathrm{Ra} 0.343 \mu \mathrm{m}$ to $\mathrm{Ra} 0.114 \mu \mathrm{m}$ corresponding to the Case I in the section 2.2 .

In the Figure 8, after ultrasonic machining, the chip size is more uniform. Conventional milling generate larger deformation and receive greater cutting force. And, uniform chip morphology with different sizes and deformation, implies uniform machining surfaces. Strongly surface deformed chip morphology also results in uneven surface formation. Comparisons of the chips morphology using CM method, the chips of front side view in UVAM process shows more uniformed in the view of Figure 8(c), Figure $8(\mathrm{~g})$, Figure $8(\mathrm{k})$ and Figure $8(\mathrm{o})$. There are obviously fracture gaps between adjacent chips and the size of chip smaller than that in CM process. Ultrasonic generator can provide a high frequency cutting force excitation contributing to refine the size of chips.
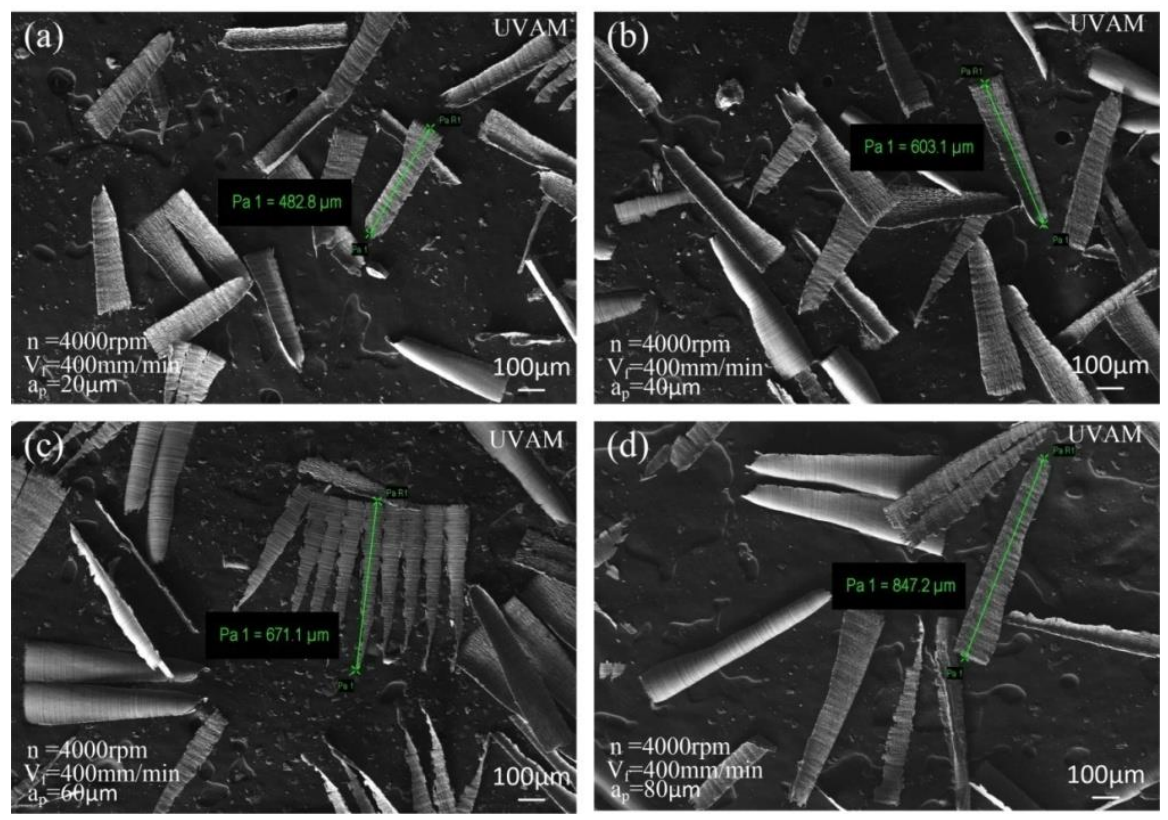

Figure 9. The cutting chips of first path in the beginning UVAM cutting in $n=4000 \mathrm{rpm}$ and $V_{f}=400 \mathrm{~mm} / \mathrm{min}$ : (a) $a_{p}=20 \mu \mathrm{m}$; (b) $a_{p}=40 \mu \mathrm{m}$; (c) $a_{p}=60 \mu \mathrm{m}$; (d) $a_{p}=80 \mu \mathrm{m}$

In the first cutting path of each group of cutting experiment, the cutting tool front is all involved in cutting. So in this condition the cutting chips are more bigger than other path. Cutting chips in first path display in the Figure 9 both in UVAM and CM process, 
in which the morphology, size and length of cutting chips are different with each other, especially elongating from $482.8 \mu \mathrm{m}$ to $847.2 \mu \mathrm{m}$ along with the cutting depth increasing. Cutting chips is more small and more scattered in UVAM process that results in the cutting force decreasing compared to the CM process in which the chips attached to each other in a petal shape cut by in the adjacent area. Tear mark, which was a main source of cutting force, was also found in the broad end of the chip.

\subsection{Surface residual stresses}

Surface residual stresses measurements were conducted on a calibrated residual stress analyzer (Stresstech Group, XSTRESS ROBOT, Finland) which is in a high precision level. Two direction residual stresses have been measured alone the slot direction (longitudinal direction) on the surface and the direction perpendicular to the slot (transversal direction). After surface roughness analysis, we can easily validate the roughness value obvious difference between $4000 \mathrm{rpm}$ to $5000 \mathrm{rpm}$. So in residual stresses analysis, we reasonable focus on the spindle speed between $4000 \mathrm{rpm}$ to 5000 $\mathrm{rpm}$. In this research, residual stresses value have been acquired in two direction among 128 groups experiments both in longitudinal and transversal direction with and without processing by ultrasonic assistance. Since the residual stresses depends on the inhomogeneous deformation of the cutting process, we take the cutting depth value of $a_{p}$ smallest value of $20 \mu \mathrm{m}$ and largest value of $80 \mu \mathrm{m}$ into special consideration. Besides, the surface processing under UVAM can reduce the different between two directions than that manufactured in CM process. It was also possible to identify a tendency to residual stresses in UVAM more likely to produce a lower residual compressive stress compared to CM processing.

Figure 10 summarizes the slots bottom surface residual stresses with UVAM and CM processing in depth of cut $20 \mu \mathrm{m}$ and $80 \mu \mathrm{m}$ on the spindle of $4000 \mathrm{rpm}$ and 5000 rpm respectively. Obviously, Figure 10(a) and 10(c) show that UVAM processing both in longitudinal and transversal direction with different value of $a_{p}$. We can observe the residual stresses value of $a_{p}=80 \mu \mathrm{m}$ higher compared to $a_{p}=20 \mu \mathrm{m}$ in $4000 \mathrm{rpm}$, and exhibited an opposite trend in $5000 \mathrm{rpm}$ both in longitudinal and transversal direction. But the trend of residual stresses of surface processed by CM makes a difference between longitudinal and transversal direction in variable depth of cutting. Without ultrasonic assistance process, the residual stresses in $a_{p}=80 \mu \mathrm{m}$ always higher than the $a_{p}=20 \mu \mathrm{m}$ due to the intense deformation in bigger depth of cutting. Apparent differences in surface stresses between the same depth of cutting by different machining method can be clearly observed in Figure 10(e) and Figure 10(f). 

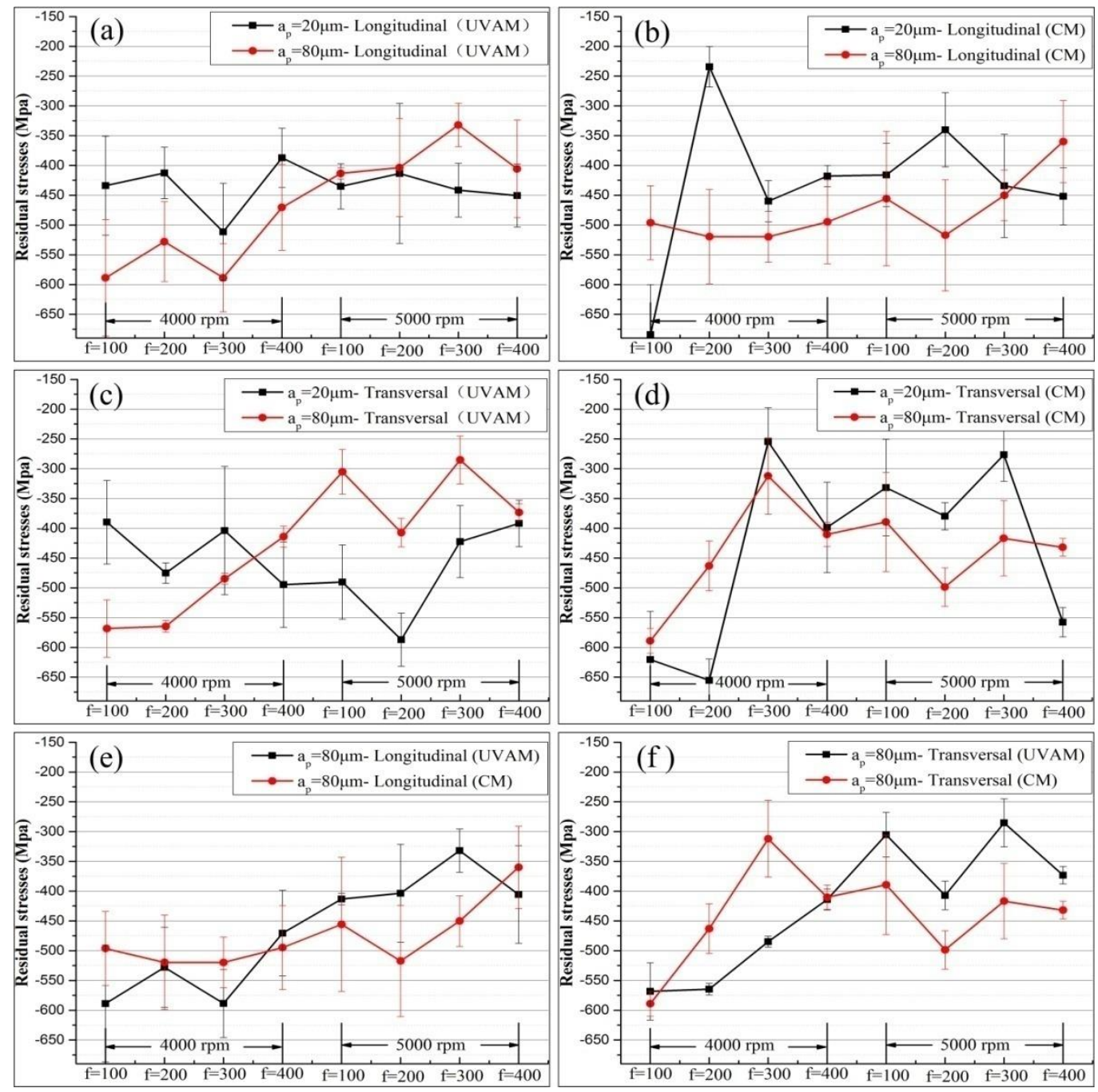

Figure 10. The residual stresses with UVAM and CM in $4000 \mathrm{rpm}$ and $5000 \mathrm{rpm}$

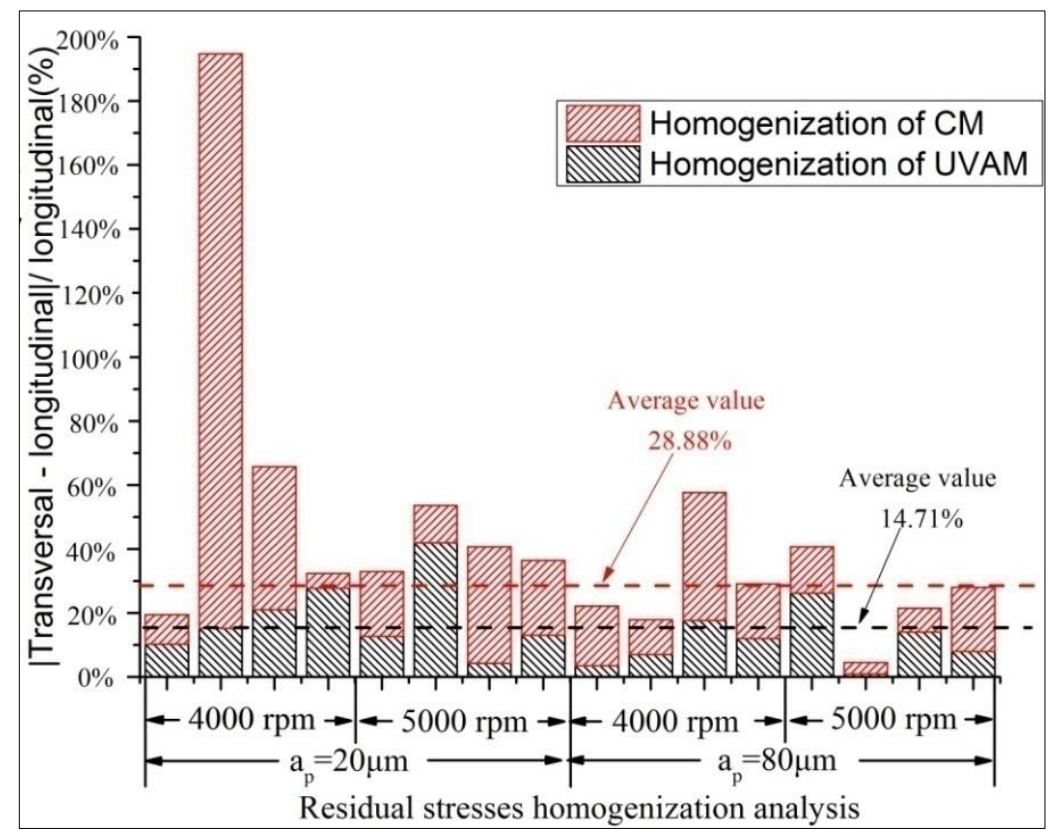

Figure 11. The homogenization of residual stresses analysis 
Figure 11 displays the homogenization about surface residual stresses of slots surface. The homogenization takes the transversal-longitudinal ratio into consideration. The transversal-longitudinal ratio is the absolute of value of transversal-longitudinal to the longitudinal value. The homogenization of residual stress is $14.71 \%$ in UVAM, which is also considerably improved as compared with $28.88 \%$ in the traditional milling. Furthermore, we can clearly find the homogenization of ball-end milling with ultrasonic assistance in black bar is more lower than homogenization of CM in red bar in Figure 11 .

\subsection{The topography of the cutting surface}

In order to observe the real appearance of workpiece slots bottom surface, micrograph was captured under a digital microscope with ultra-depth of field digital microscope microscopy (Smartzoom5, ZEISS, Germany), and in Figure 12(a) is the surface machined by parameter $n=5000 \mathrm{rpm}, V_{f}=200 \mathrm{~mm} / \mathrm{min}, a_{p}=20 \mu \mathrm{m}$ by CM, and the plastic deformation can be seen clearly in this graph corresponding to the Case II in the section 2. By comparasion, Figure 12(b) shows the uniform surface with the vibration marks machined by the same cutting parameter by UVAM processing. There is a significant difference between the surfaces of two manufacture methods. The surface is strongly squeezed to form a messy surface topography in Figure 12(a) by CM process which is another proof of plastic deformation in center point of ball-end mill in section 2.2. This types of squeezed surfaces imply non-uniform friction, higher cutting forces, and rapid tool wear; In Figure 12(b), the homogenized and uniform surface was machined by UVAM. Ultrasonic assistance, in same scale, increases the rigidity of the tool, reduces the cutting force in cutting region. Thus, UVAM reduced the surface inhomogeneous deformation on the surface of workpiece.

To further study the micro texture on the surface, laser confocal microscope (LSM700, ZEISS, Germany) is used to analyze the surface in more detail. As show in Figure 13, there are four different machining methods [6,17] at spindle speed of 4000 rpm and $5000 \mathrm{rpm}$ with and without ultrasonic assisted. With the same cutting depth of $20 \mu \mathrm{m}$, the trace of the cutting tool left on the surface is not uniformed and roughness at the $4000 \mathrm{rpm}$ without ultrasonic assistance just shown as Figure 13(a). Although, with the same parameter under UVAM, the topography has also same little uniformed defect which like seedlings rowed up on the surface deformed by cutting interval residual height (the model has been established in the section 2.2) just as show in Figure 13(b). In addition, the topography at $5000 \mathrm{rpm}$ is not uniform and the roughness is lower than which at $4000 \mathrm{rpm}$ in Figure 13(c). Comparasion with Figure 13(a)-(c), topography in Figure 13(d) with ultrasonic applied, is more homogeneous and the roughness is the lowest among four pictures. Moreover, the surface homogenization effects of surface is the most significant one among all parameters.

The uniform residual height of cutting left by the center point of ball-end milling cutter where the cutting speed is at approximately zero with CM. On the contrary, the residual height decrease significantly machined by UVAM process. Furthermore, there are some defects on the bottom of Figures 13(a), 13(b) and 13(c) that we can easily 
detect. By observing and comparing the topographies of machined surfaces, it is found that ultrasonic vibration-assisted milling can reduce surface defects and obtain more uniform machined surfaces.

In the surface analysis in the Figure 14, the smallest chip was found adhered to the workpiece which was cleaned by a ultrasonic cleaners immersing in alcohol and then dried in the air. The chip size is less than $5 \mu \mathrm{m}$. After detected by SEM, we used EDS chemical elements analysis to find the main chemical elements in the smallest chip were $\mathrm{Ti}, \mathrm{Al}, \mathrm{V}$ and $\mathrm{C}$ et al. elements. So we can conclude the smallest chip is a part of the workpiece validating the assumption of Section 2.2 Case I .
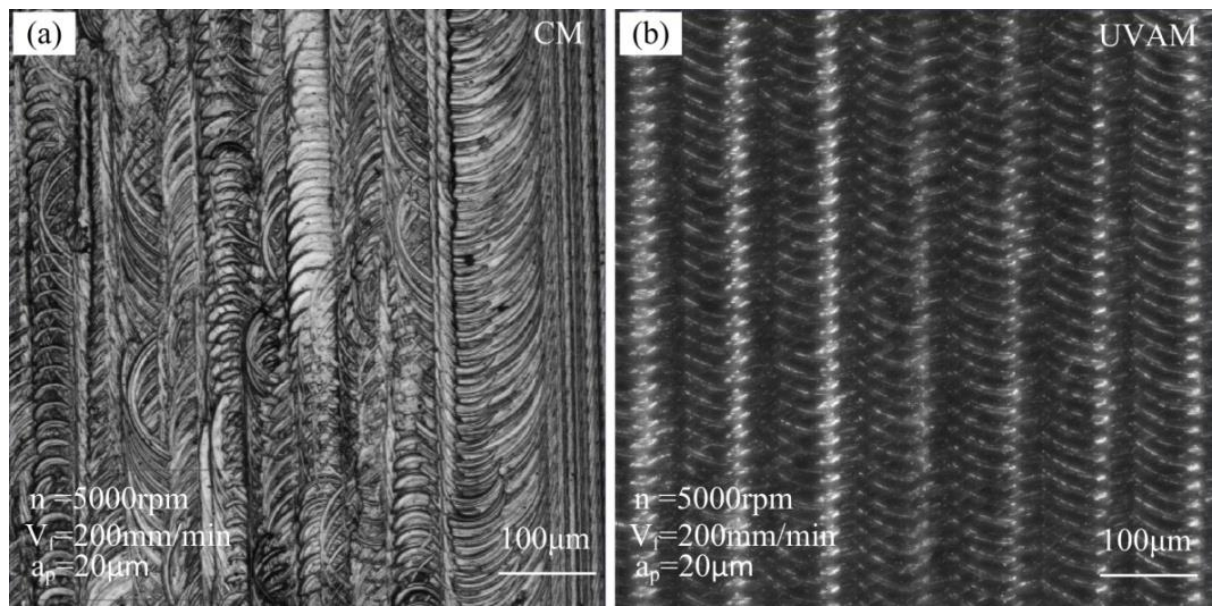

Figure 12. The slot bottom surface in detail: (a) the surface machined by CM; (b) the surface machined by UVAM.
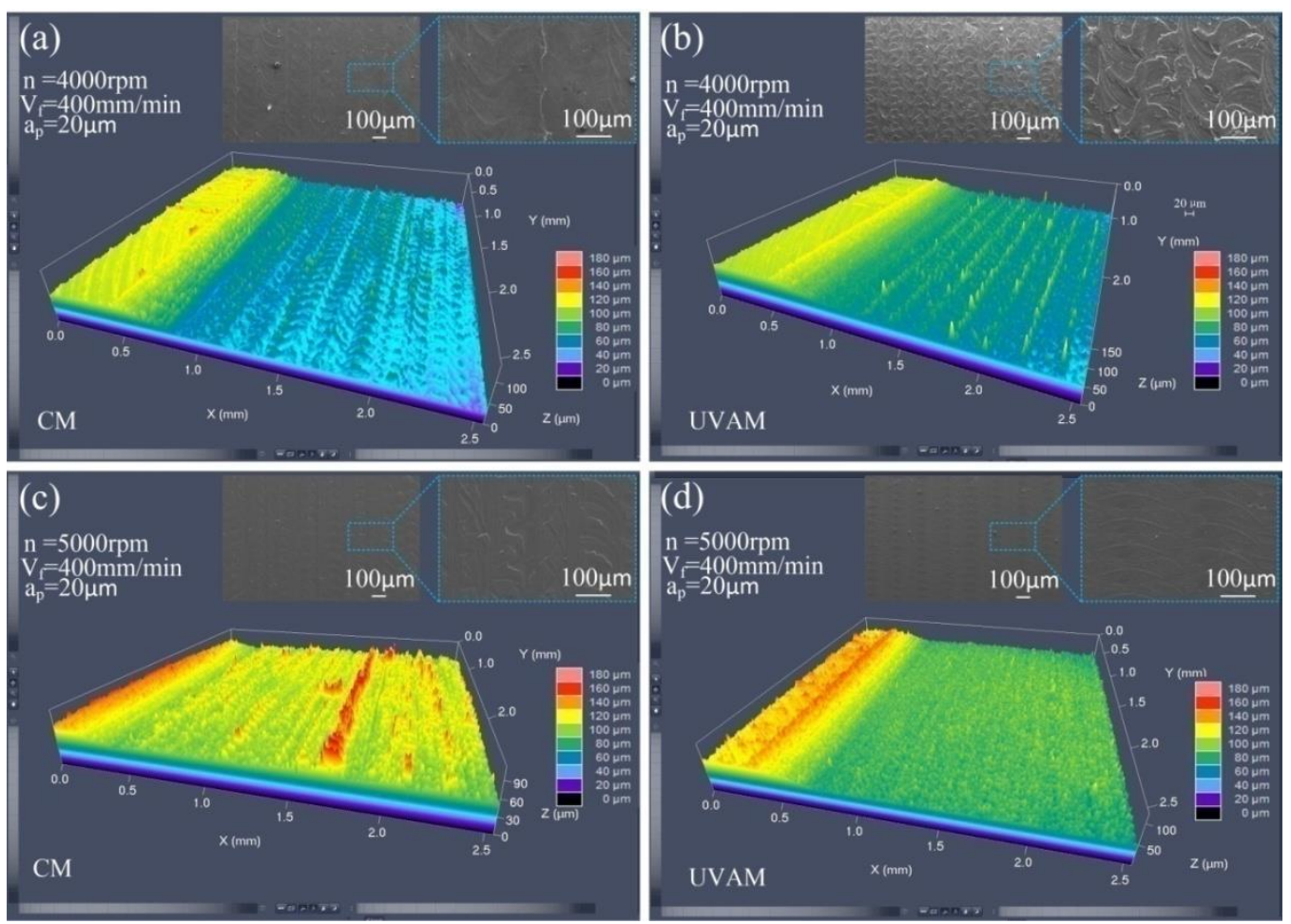

Figure 13. The topography of the bottom of slots in which $V_{f}=400 \mathrm{~mm} / \mathrm{min}, a_{p}=20 \mu \mathrm{m}$ : (a) CM in $n=4000$ rpm; (b) UVAM in $n=4000 \mathrm{rpm}$; (c) CM in $n=5000 \mathrm{rpm}$; (d) UVAM in $n=5000 \mathrm{rpm}$ 


\subsection{Tool damage characterisation}

Vibration of cutting tool has reportedly allowed a high reduction of cutting forces, low tool wear up to $25-40 \%$, as well as roundness improvements up to $40-50 \%$ [29]. In this cutting experiments, 256 groups of testing were divided into two parts with the same cutting time. There are total two mills in the full experiments, each ball-end mill was dedicated to a separate frequency in certain part and the other is in the same situation. In order to isolate the impact of the frequency on tool wear or damage. The tip of each tool is analyzed under a scanning electron microscope. Tool fracture, formation, crater, side tearing damage and built-up-edge (BUE) were detect in detail and reason analysis. Without ultrasonic vibration assisted, literatures pointed out that BUE was continuously generated and accumulated on the tip of tool, so cutting forces got higher and cutting edge state got worse [8].
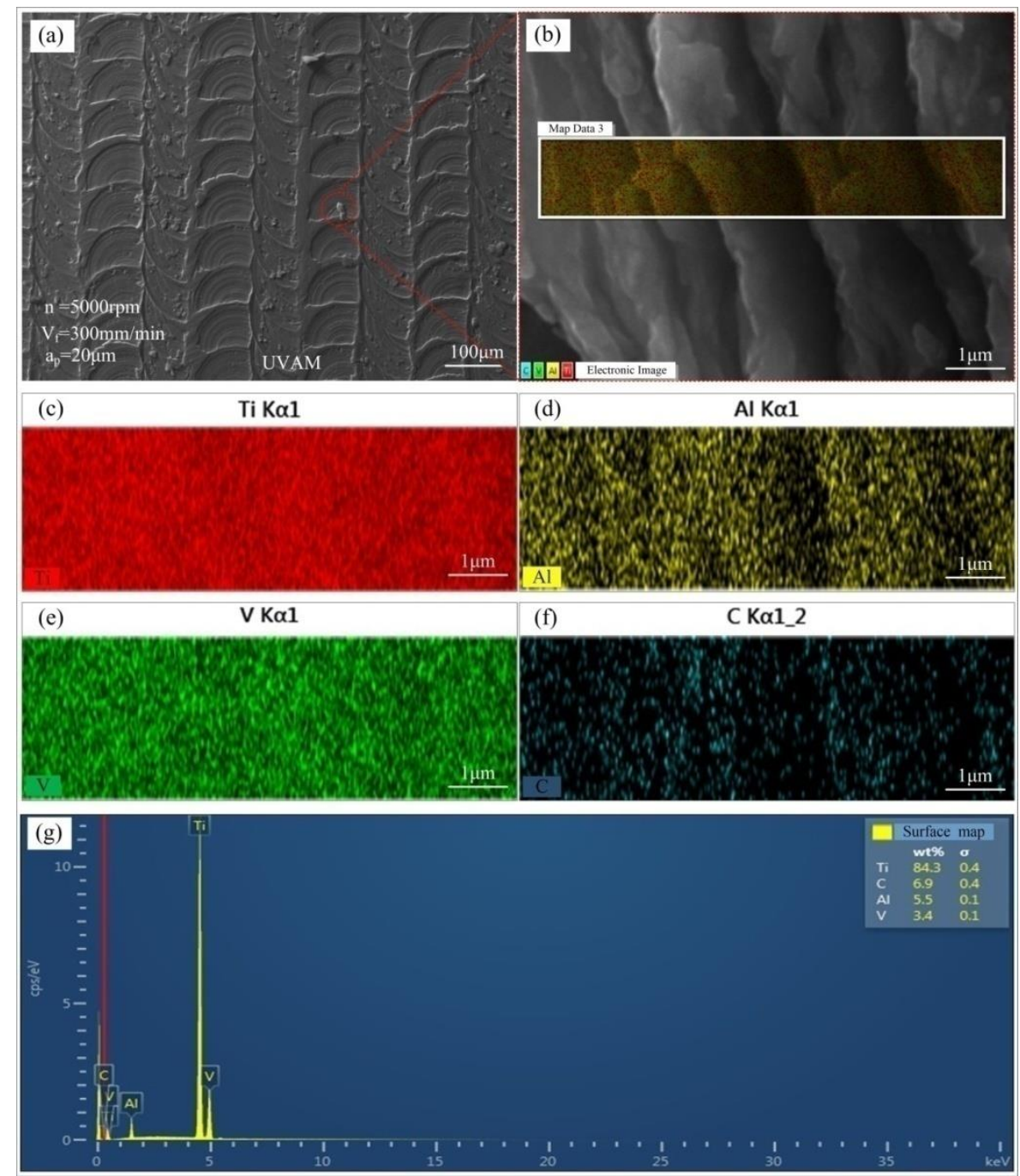

Figure 14. Observation of smallest chip on the surface of the workpiece: (a): the workpiece cutting by

UVAM process; (b): the enlarge view of the smallest chip; (c): the distribution diagram of chemical element of Ti; (d): the distribution diagram of chemical element of Al; (e): the distribution diagram of chemical element of V; (f): the distribution diagram of chemical element of $\mathrm{C}$; (g): the surface total map of chemical elements 

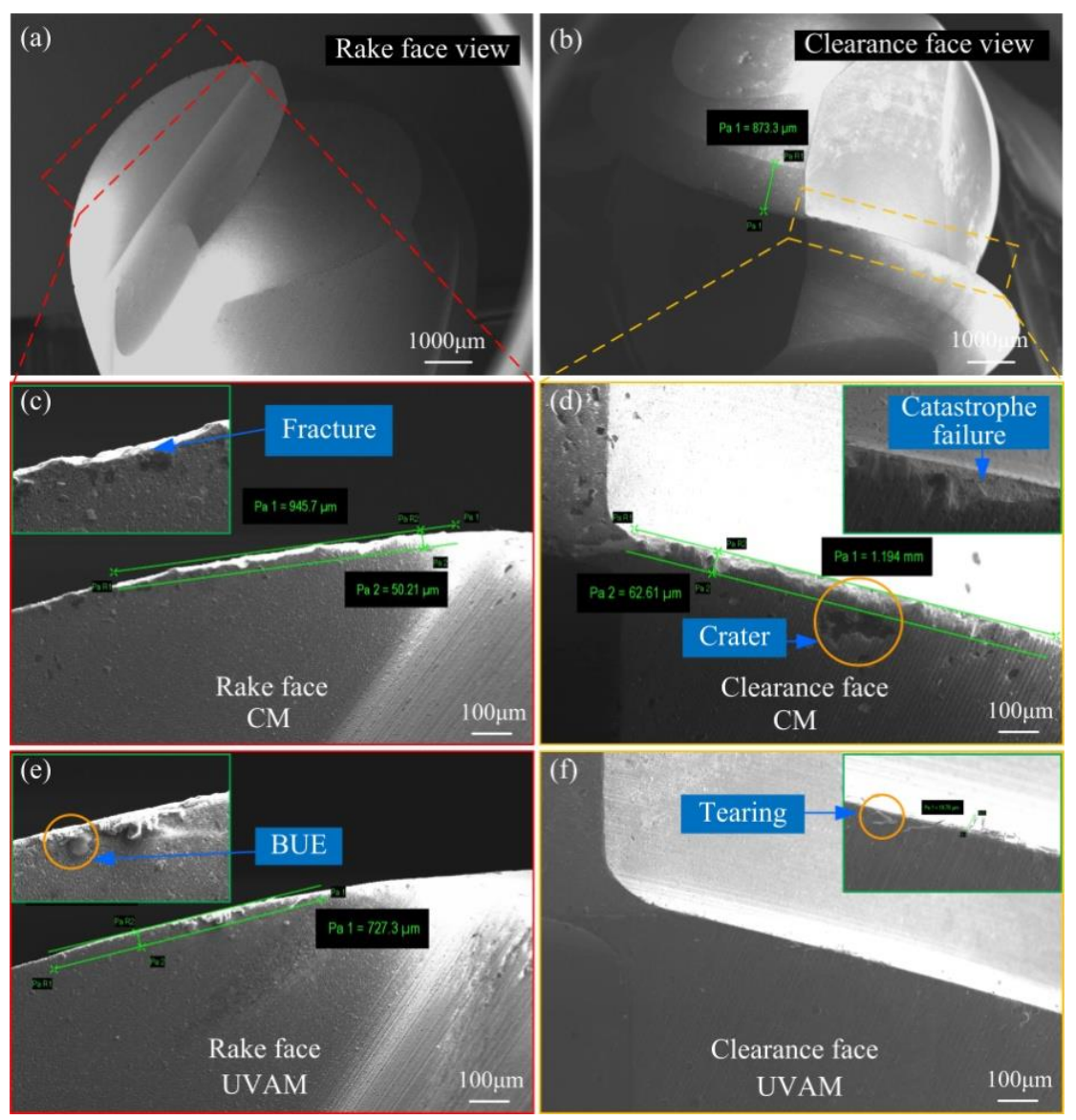

Figure 15. Scanning electron micrograph of tool wear in both UVAM and CM process:(a) is the rake face view of mill; (b) is clearance face view of mill; (c) is the tool wear in the rake face view and enlarge view of mill machined by $\mathrm{CM}$; (d) is the tool wear in the rake face view and enlarge view of mill machined by UVAM; (e) is the tool wear in the clearance face view and enlarge view of mill machined by CM; (e) is the tool wear in the clearance face view and enlarge view of mill machined by UVAM

Figure 15 presents tool wear in UVAM are desirable lower than that of those in CM process both compared in area value and length value. The rake faces and clearance faces of cutting tools are damaged in different degree. Without ultrasonic assistance, the area and length of damage on tool such as fracture, catastrophe failure and crater is illustrated in the Figure 15(c) and 15(d) graphs. In CM process, the damage length on rake face reaches up to $945.7 \mu \mathrm{m}$. The length of damage on clearance face reaches up to $1194 \mu \mathrm{m}$. With ultrasonic vibration assistance, there are just a little BUE adhere to the rake face and some tearing fiber on the clearance face in the Figure 15(e) and Figure 15(f) graphs. In UVAM process, the damage length on rake face reaches up to $727.3 \mu \mathrm{m}$ shorter than ones in CM process. Almost no damage is on clearance face except some tearing fiber.

Consequently, UVAM process prolonged the service cutting tool life, with the same cutting distance of all the cutting experiments compared to the CM process. 


\section{Conclusions}

In this study, we investigate the machining effect of UVAM under the conditions of ultrasonic excitation, focusing on surface homogenization and integrity. At the same time, the test data are compared with those using the common milling method. To find out the causes for the homogenization, we establish the cutting residual height models for the surface of TI-6Al-4V parts in both the transversal and longitudinal residual direction, and discuss the machining mechanism of ultrasonic ball-end milling surface. Ultrasonic milling machining consists of three machining methods, including the normal milling, ultrasonic vibration milling and ultrasonic extrusion. We establish a qualitative modeling of surface roughness, highlighting the role of ultrasonic vibration in ball-end milling. In the study of surface integrity, key parameters such as cutting force, surface roughness, residual stresses, surface topography, cutting chips topography and tool wear charicterization, are analyzed. The innovations of this paper are as follows:

1. UVAM with ball-end milling is employed to machine complex part flat surface and freeform surface. It is not necessary to tilt the tool and exchange the tool during the whole precision milling process, which saves the time of tool replacement, and reduces the errors caused by repeated positioning and tool replacement, allowing the three-axis milling center to partially possess the functions of the five-axis milling center.

2. During the experiment, we can conclude the roughness value $\mathrm{Ra}$ is below $0.27 \mu \mathrm{m}$ in ball-end milling with the spindle speed exceed $5000 \mathrm{rpm}$. It is found that when ultrasonic vibration is used to machine the surface of the workpiece, the surface roughness changes significantly from $4000 \mathrm{rpm}$ to $5000 \mathrm{rpm}$. The surface roughness averages Ra $0.828 \mu \mathrm{m}$ in a range of $3000-4000 \mathrm{rpm}$. However, it decreases to Ra 0.129 $\mu \mathrm{m}$ in a range of 5000-6000 rpm. In the range of the experimental parameters, when the spindle speed exceeds $5000 \mathrm{rpm}$, that is, the spindle speed single-tooth frequency is $83.3 \mathrm{~Hz}$, and the ultrasonic frequency is approximately $25 \mathrm{kHz}$, the parameters are matched rationally, and the torsional vibration greatly increases the rotation speed of spindle to some extent.

3. Online high frequency cutting force was measured during the cutting by a new established measurement system. Cutting force signal with ultrasonic excitation applied can significantly reduce the surface roughness of machined parts and slightly reduce the cutting force. The cutting force is not processed by the Dynoware software, as the sampling frequency of this software can no longer satisfy the $25 \mathrm{KHz}$ measurement requirements of the ultrasonic vibration tool holder. We adopt Kistler's dynamometer and charge amplifier hardware and $\mathrm{m}+\mathrm{p}$ international's VibRunner data acquisition system and SO Analyzer to collect the cutting force data. The results validate the high frequency cutting force signal collected plays an important role in the cutting process.

4. In the process of surface homogeneity research, it is found that the homogenization by UVAM with ball-end milling is rather obvious in terms of surface roughness and surface residual stress. We use the ratio of the absolute value of the transverse-longitudinal difference to the longitudinal value as the evaluation index. The 
homogenization of roughness in UVAM is $17.95 \%$, which is significantly improved as compared with $61.18 \%$ in the conventional milling; The homogenization of residual stress is $14.71 \%$ in UVAM, which is also considerably improved as compared with $28.88 \%$ in the traditional milling;

5. We have conducted ultrasonic vibration assisted ball-end continuous precision milling experiments, and have carried out 256 groups of experiments to measure surface roughness, 128 groups of experiments to measure residual stress, 64 groups of experiments to measure online cutting force and a multiple groups of experiments to measure workpiece surface topography, tool wear topography and cutting topography using the SEM microscope, which provides sufficient reference for subsequent research on UVAM with ball-end milling.

Author Contributions: Jinkai $\mathrm{Xu}$ and Huadong $\mathrm{Yu}$ conceived and supervised the project. Wanfei Ren performed the modeling and conducting experiments and wrote the manuscript. And Zhanjiang Yu give constructive suggestions on paper. Zhongxu Lian and Peng Yu analyzed the data and modified syntax and errors.

Funding: This work was supported by China-EU H2020 International Science and Technology Cooperation Programme (FabSurfWAR Nos.2016YFE0112100 and 644971), Jilin Province Science and Technology Development Program Supported Project(20180201057GX)

Acknowledgments: The authors wish to acknowledge the financial support of ChinaEU H2020 International Science and Technology Cooperation Programme (FabSurfWAR Nos.2016YFE0112100 and 644971), Jilin Province Science and Technology Development Program Supported Project(20180201057GX) and the "111" Project of China (D17017). 


\section{References}

1. Milton C, Shaw. Metal cutting principles. Oxford University Press 2005, 2, 9-14.

2. Cong, W.; Pei, Z. Handbook of manufacturing engineering and technology, Process of ultrasonic machining. Springer-Verlag London 2015, 45, 1630-1648.

3. Zhou, Ming.; Eow, Y. T.; Ngoi, B. K. A.; Lim, E. N. Vibration-assisted precision machining of steel with PCD tools. Adv. Manuf. Proc. 2003, 18(5), 825-834.

4. Nath, C.; Rahman, M. Effect of machining parameters in ultrasonic vibration cutting. Int. J. Mach. Tool. Manuf. 2008,48(9), 965-974.

5. Maurotto, A.; Muhammad, R.; Roy, A.; Silberschmidt, V. V. Enhanced ultrasonically assisted turning of a $\beta$-titanium alloy. Ultrasonics 2013, 53(7), 12421250.

6. Babitsky, V. I.; Kalashnikov, A. N.; Meadows, A.; Wijesundara, A. A. H. P. Ultrasonically assisted turning of aviation materials. J. Mater. Process. Tech. 2003, 132(1-3), 157-167.

7. Geng, D.; Zhang, D.; Xu, Y.; He, F.; Liu, F. Comparison of drill wear mechanism between rotary ultrasonic elliptical machining and conventional drilling of CFRP. J. Reinf. Plast. Comp. 2014, 33(9), 797-809.

8. Zhou, M.; Wang, M.; Dong, G. Experimental investigation on rotary ultrasonic face grinding of SiCp/Al composites. Adv. Manuf. Process. 2016, 31(5), 673-678.

9. Zhu, X.; Lin, B.; Liu, L.; Luan, Y. Power transfer performance and cutting force effects of contactless energy transfer system for rotary ultrasonic grinding. IEEE T. Ind. Electron. 2016, 63(5), 2785-2795.

10. Sun, Z.; To, S. Effect of Machining Parameters and Tool Wear on Surface Uniformity in Micro-Milling. Micromachines. 2018, 9, 268-282.

11. Gao, P.; Liang, Z.; Wang, X.; Zhou, T.; Xie, J.; Li, S.; Shen, W. Fabrication of a micro-lens array mold by micro ball end-milling and its hot embossing. Micromachines 2018, 9(3), 96-107.

12. Zhang, X.; Kornel, F. Ehmann.; Yu, T.; Wang, W. Cutting forces in micro-endmilling processes. Int. J. Mach. Tool. Manuf. 2016, 107, 21-40.

13. Tangjitsitcharoen, S.; Thesniyom, P.; Ratanakuakangwan, S. Prediction of surface roughness in ball-end milling process by utilizing dynamic cutting force ratio. $J$. Intell. Manuf. 2014, 28, 1-9.

14. Fontaine, M.; Moufki, A.; Devillez, A.; Dudzinski, D. Modelling of cutting forces in ball-end milling with tool-surface inclination: Part I : predictive force model and experimental validation. J. Mater. Process. Tech. 2007, 189(1), 73-84.

15. Buj-Corral, I.; Vivancos-Calvet, J.; Domínguez-Fernández, A. Surface topography in ball-end milling processes as a function of feed per tooth and radial depth of cut. Int. J. Mach. Tool. Manuf. 2012, 53(1), 151-159.

16. Feng, P.; Wang, J.; Zhang, J.; Zhijun, W. U. Research status and future prospects of rotary ultrasonic machining of hard and brittle materials. Chin. J. Mech. Eng-En. 2017, 53(19),3-21.

17. Silberschmidt, V. V.; Mahdy, S. M. A.; Gouda, M. A.; Naseer, A.; Maurotto, A.; 
Roy, A. Surface-roughness improvement in ultrasonically assisted turning. Procedia Cirp 2014, 13, 49-54.

18. Tao, G.; Ma, C.; Bai, L.; Shen, X.; Zhang, J. Feed-direction ultrasonic vibration assisted milling surface texture formation. Adv. Manuf. Proce. 2016, 32(2), 193198.

19. Shen, X. H.; Zhang, J. H.; Li, H.; Wang, J. J.; Wang, X. C.V. Ultrasonic vibrationassisted milling of aluminum alloy. Int. J. Adv. Manuf. Tech. 2012, 63(1-4), 41-49.

20. Zhang, Y.; Zhao, B., Wang, Y.; Chen, F. Effect of machining parameters on the stability of separated and unseparated ultrasonic vibration of feed direction assisted milling . J. Mecha. Sci. Technol. 2017, 31(2), 851-858.

21. Ko, J. H.; Tan, S. W. Chatter marks reduction in meso-scale milling through ultrasonic vibration assistance parallel to tooling's axis. Int. J. Precis. Eng. Manuf. 2013, 14(1), 17-22.

22. Suárez, A.; Veiga, F.; Lacalle, L. N. L. D.; Polvorosa, R.; Lutze, S.; Wretland, A. Effects of ultrasonics-assisted face milling on surface integrity and fatigue life of Ni-Alloy 718. J. Mater. Eng. Perfor. 2016, 25(11), 5076-5086.

23. Zarchi, M. M. A.; Razfar, M. R.; Abdullah, A. Influence of ultrasonic vibrations on side milling of AISI 420 stainless steel. Int. J. Adv. Manuf. Tech. 2013, 66(1-4), 8389.

24. Hampa, P. S.; Razfar, M. R.; Malaki, M.; Maleki, A. The role of dry aero-acoustical lubrication and material softening in ultrasonically assisted milling of difficult-tocut AISI 304 steels. T. Indian I. Metals. 2015, 68(1), 43-49.

25. Abdullah, A. Investigation of the effect of cutting speed and vibration amplitude on cutting forces in ultrasonic-assisted milling. Proce. Ins. Mecha. Eng. Part B J. Eng. Manuf. 2011, 226, 1-7.

26. Khan, M. K.; Fitzpatrick, M. E.; Wang, Q. Y.; Pyoun, Y. S.; Amanov, A. Effect of ultrasonic nanocrystal surface modification on residual stress and fatigue cracking in engineering alloys. Fatigue. Fract. Eng. Mater. Struct. 2017, 41(4), 1-12.

27. Maurotto, A.; Wickramarachchi, C. T. Experimental investigations on effects of frequency in ultrasonically-assisted end-milling of AISI 316L: a feasibility study. Ultrasonics 2016, 65, 113-119.

28. Yao, Z.; Kima, G. Y.; Faidley, L. A.; Zou, Q.; Mei, D.; Chen, Z. Acoustic softening and residual hardening in aluminum: modeling and experiments. Int. J. Plasticity 2012, 39(39), 75-87.

29. Ma, C. X.; Shamoto, E.; Moriwaki, T. Study on the thrust cutting force in ultrasonic elliptical vibration cutting. Mater. Sci. Forum. 2004, 471-472, 396-400. 